\title{
Semi-Analytical Rate Decline Solutions for a Refractured Horizontal Well Intercepted by Multiple Reorientation Fractures with Fracture Face Damage in an Anisotropic Tight Reservoir
}

\author{
Mingxian Wang ${ }^{1, *}$, Xiangji Dou ${ }^{2, *}$, Ruiqing Ming ${ }^{3}$, Weiqiang $\mathrm{Li}^{4}$, Wenqi Zhao ${ }^{3}$ and Chengqian Tan ${ }^{1}$ \\ 1 School of Earth Science and Engineering, Xi'an Shiyou University, Xi'an 710065, China; \\ cqtan@xsyu.edu.cn \\ 2 School of Petroleum Engineering, Changzhou University, Changzhou 213164, China \\ 3 Research Institute of Petroleum Exploration and Development, PetroChina, Beijing 100083, China; \\ mingrq@petrochina.com.cn (R.M.); zhaowenqi@petrochina.com.cn (W.Z.) \\ 4 PetroChina Hangzhou Research Institute of Geology, Hangzhou 310023, China; \\ liwq_hz@petrochina.com.cn \\ * Correspondence: wangmingxian@xsyu.edu.cn (M.W.); gewuyangming@163.com (X.D.)
}

\section{check for} updates

Citation: Wang, M.; Dou, X.; Ming, R.; Li, W.; Zhao, W.; Tan, C. Semi-Analytical Rate Decline Solutions for a Refractured Horizontal Well Intercepted by Multiple Reorientation Fractures with Fracture Face Damage in an Anisotropic Tight Reservoir. Energies 2021, 14, 7482. https://doi.org/ $10.3390 /$ en14227482

Academic Editor: Reza Rezaee

Received: 15 October 2021

Accepted: 8 November 2021

Published: 9 November 2021

Publisher's Note: MDPI stays neutral with regard to jurisdictional claims in published maps and institutional affiliations.

Copyright: (c) 2021 by the authors. Licensee MDPI, Basel, Switzerland. This article is an open access article distributed under the terms and conditions of the Creative Commons Attribution (CC BY) license (https:// creativecommons.org/licenses/by/ $4.0 /)$.

\begin{abstract}
Refracturing treatment is an economical way to improve the productivity of poorly or damaged fractured horizontal wells in tight reservoirs. Fracture reorientation and fracture face damage may occur during refracturing treatment. At present, there is still no report on the rate decline solution for refractured horizontal wells in tight reservoirs. In this work, by taking a semi-analytical method, traditional rate decline and Blasingame-type rate decline solutions were derived for a refractured horizontal well intercepted by multiple reorientation fractures with fracture face damage in an anisotropic tight reservoir. The accuracy and reliability of the traditional rate decline solution were verified and validated by comparing it with a classic case in the literature and a numerical simulation case. The effects of fracture reorientation and fracture face damage on the rate decline were investigated in depth. These investigations demonstrate that fracture face damage is not conducive to increasing well productivity during the early flow period and there is an optimal matching relationship between the principal fracture section angle and permeability anisotropy, particularly for the reservoirs with strong permeability anisotropy. The fracture length ratio and fracture spacing have a weak effect on the production rate and cumulative production while the fracture number shows a strong influence on the rate decline. Furthermore, multifactor sensitivity analysis indicates that fracture conductivity has a more sensitive effect on well productivity than fracture face damage, implying the importance of improving fracture conductivity. Finally, a series of Blasingame-type rate decline curves were presented, and type curve fitting and parameter estimations for a field case were conducted too. This work deepens our understanding of the production performance of refractured horizontal wells, which helps to identify reorientation fracture properties and evaluate post-fracturing performance.
\end{abstract}

Keywords: semi-analytical rate decline solutions; reorientation fracture; fracture face damage; horizontal well; permeability anisotropy; tight reservoir

\section{Introduction}

Compared to drilling more new wells, refracturing low-production horizontal wells in tight reservoirs (particularly for those poorly or damaged fractured wells) has been chosen by many international petroleum companies to enhance oil recovery and enable commercial production with relatively low investment [1-3]. During refracturing treatment, fracture reorientation may occur under the combined effects of the initial fracture propagation and the nonuniformly decreased pore pressure, resulting in reorientation fractures around initial 
hydraulic fractures (Figure 1) [4]. On one hand, the newly formed fractures deviate from those fractures induced by initial fracturing and reorient and propagate at other azimuthal angles; on the other hand, these new fractures may undergo secondary reorientation and eventually form non-coplanar reorientation fractures (Figure $1 b$, hydraulic fracture E) $[5,6]$. Of course, during this treatment, certain hydraulic fractures induced by initially fracturing may further propagate and reorient, and also form reorientation fractures (Figure 1b, hydraulic fracture $\left.\mathrm{B}^{\prime} / \mathrm{D}^{\prime}\right)$. Naturally, some initial hydraulic fractures may permanently lose seepage capacity during refracturing (Figure $1 \mathrm{~b}$, hydraulic fracture $\mathrm{A}^{\prime} / \mathrm{C}^{\prime}$ ). These fracture propagations and reorientations finally form a complex reorientation fracture network near horizontal wellbores (Figure 1b). Meanwhile, fracturing fluid loss always leads to permeability damage near fracture faces and creates damaged zones around the newly formed fractures [7]. The production rates in tight reservoirs always show a rapid decline after high-peak production [8,9], but fracture reorientation and fracture face damage further exacerbate the uncertainty of well production and present more challenges to the rate decline prediction of refractured horizontal wells, which is one of the most concerning issues after refracturing treatment.

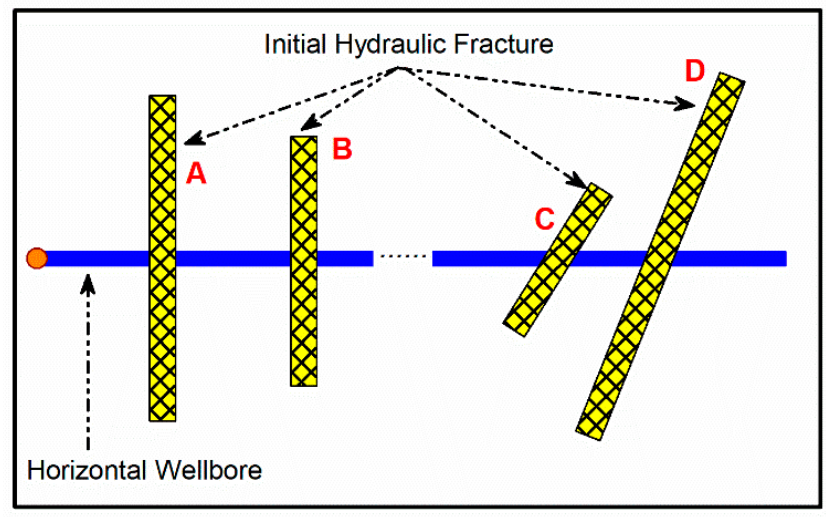

(a)

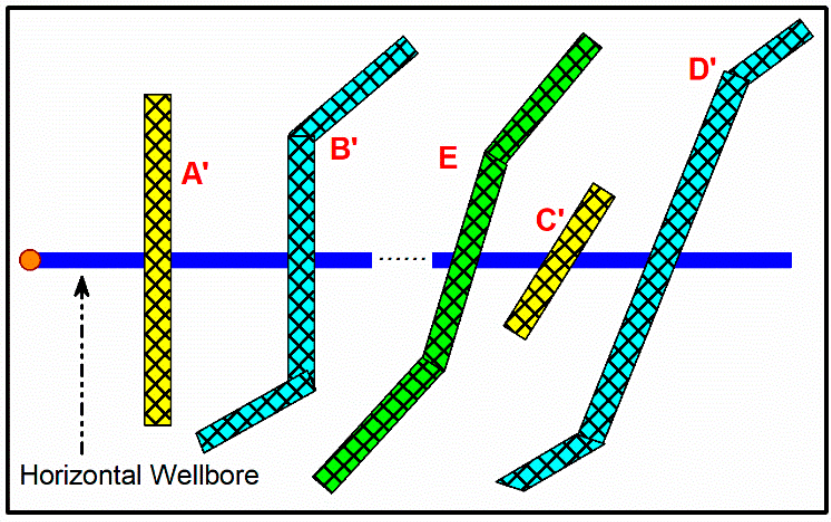

(b)

Figure 1. Comparison of fracture spatial distribution in one fractured horizontal well before and after refracturing treatment (map view). (a) Fracture spatial distribution of an initially fractured horizontal well in a rectangular reservoir (before refracturing). All initial hydraulic fractures are coplanar, orthogonal (A/B), or oblique (C/D) to horizontal wellbore. (b) Fracture spatial distribution of a refractured horizontal well in a rectangular reservoir (after refracturing). Hydraulic fracture $\mathrm{A}^{\prime} / \mathrm{C}^{\prime}$ (yellow color): Poor initial fracturing fractures lose seepage capacity and do not contribute to well production. Hydraulic fracture $\mathrm{B}^{\prime} / \mathrm{D}^{\prime}$ (cyan color): Reorientation fractures are formed by the continued propagation and reorientation of initial fracturing fractures. Hydraulic fracture E (green color): Reorientation fractures are entirely new fractures created by refracturing treatment.

As one of the most robust methods, rate decline analysis has been widely used in well tests to predict well productivities and invert reservoir properties [10-13]. By matching the rate data in the field with the predicted productivity, Arps [14] first proposed three empirical types of rate decline curves: Exponential type, harmonic type, and hyperbolic type. These equations become the basis of the rate decline analysis and are widely adopted in various conventional reservoirs; however, this method is only suitable for boundarydominant flow. In order to remedy this deficiency, Fetkovich [15] established new rate decline curves by taking the transient flow region into consideration. Unfortunately, both the Arps method and the Fetkovich method cannot handle the problem of variable wellbore pressure and variable flow rate. To solve this problem, Blasingame et al. [16,17] presented a new rate decline solution with the pressure integral method, which lays a solid foundation for modern rate decline analysis and reduces the fitting error between the production data in the field and theoretical analysis. With the development boom of unconventional reservoirs, reservoir engineers find that when applying the Arps, Fetkovich, or Blasingame method to these reservoirs, it is rather difficult to fit the high production rate in the short term, and simultaneously, the decreasing rate in the transient flow period and the flat 
decline in the long term $[8,9]$. A reasonable explanation for this phenomenon is that the low permeability of unconventional reservoirs and the complex fracture network caused by hydraulic fracturing around the wellbores are beyond the applicability of the above methods [9,15-18]. Under the circumstances, an accurate rate decline analysis of complex fractured wells in unconventional reservoirs has become significant and critical, and therefore the original intention and motivation of this study is to develop a rate decline solution of refractured horizontal wells.

More and more researchers have devoted attention to flow behavior in hydraulic fractures and have reached a basic consensus that long periods of linear flow are exhibited in hydraulically fractured wells and may continue for several years in unconventional reservoirs [19-22]. However, the efficient development of unconventional reservoirs urgently needs progress in rate decline analysis of hydraulically fractured wells. Chen and Teufel [23] established a new set of Fetkovich-type curves for tight gas evaluation, which extends a short-term flow regime to include near-linear up to pure-linear flow. Zhang et al. [24] established a multi-fractured horizontal well model with discontinuous micro-fractures and stimulated reservoir volume in a shale gas reservoir and researched the effects of a net-fracture system, micro-fractures, and fracture permeability on the rate decline. Wang et al. [25] developed a semi-analytical model for multi-fractured horizontal wells in heterogeneous reservoirs and discussed the influence of reservoir heterogeneity, fracture conductivity, and fracture length on the rate decline curves. He et al. [26] presented an improved rate-transient analysis model of multi-fractured horizontal wells, and the combined curves were developed to investigate the effects of non-uniform properties of hydraulic fractures on transient rate behaviors. Hu et al. [27] proposed a new rate decline model of horizontal wells with variable conductivity and uneven distribution of multiple fractures and studied the influence of the fracture spacing, fracture length, fracture conductivity, and fracture dip angle on the production rate. These models provide many valuable ideas for establishing fractured horizontal well models and obtaining their rate decline solutions. However, all the hydraulic fractures in these models are coplanar, which is rather different from the non-coplanar reorientation fractures formed by refracturing treatment in this study.

In terms of reorientation fractures, several scholars began to focus on the influence of refracturing treatment on transient pressure or pseudo-steady productivity of refractured wells in recent years. Teng and Li [28] proposed a semi-analytical method to evaluate the performance of a refractured vertical well with different types of reorientation fractures. Wu et al. [29] developed a semi-analytical model for a vertical well with a single reorientation fracture by the nodal analysis technique to analyze the effects of reorientation fracture properties on its transient pressure. Wang et al. [30] established a semi-analytical model for a horizontal well with multiple finite conductivity reorientation fractures to investigate the impacts of fracture reorientation on pseudo-steady-state productivity. Jiang et al. [13] formulated a theoretical model to evaluate the production decline performance of a fractured vertical well with reorientated fractures in an anisotropic formation and examined the effect of orientated fractures by generating Agarwal-Gardner-type decline curves. Real-time diagnostic techniques have been recognized as potential tools for preand post-refracturing analysis [31,32], but there is no report on the instantaneous rate decline solution of refractured horizontal wells, and the influence of reorientation fracture properties on the instantaneous rate decline is still unknown.

Besides the difficulty of rate decline analysis brought about by fracture reorientation, fracture face damage caused by fracturing fluid loss [7] adds extra difficulty to rate decline analysis for refractured horizontal wells. At present, there are several studies on the influence of fracture face damage on transient pressure or well-test analysis. Evans [7] first defined fracture face damage existing in fractured wells and derived the equations to calculate the pressure drop across the fracture face damage zone. Later, Cinco-Ley and Samaniego [33] redefined the dimensionless skin damage factor and discussed the effect of fracture face damage on the transient pressure in detail. Wang et al. [34] 
established a vertical well model intercepted by a finite-conductivity vertical fracture with skin damage and investigated how this kind of damage affected the productivity of a fractured vertical well. Overall, fracture face damage is an important source of fractured well damage and has a non-negligible influence on the evaluation of post-refracturing rate decline. To the best of our knowledge, the above literature does not consider the combined effects of fracture reorientation and fracture face damage on the instantaneous rate decline of refractured horizontal wells. Therefore, in this paper, we attempt to develop rate decline solutions for a refractured horizontal well intercepted by multiple reorientation fractures with fracture face damage in tight reservoirs, which can deepen our understanding of the production performance of refractured horizontal wells and help to identify the reorientation fracture properties and evaluate the post-refracturing performance.

This work is organized as follows: In Section 2, the basic physical descriptions and assumptions of the model in this work are made, in detail. In Section 3, a semi-analytical instantaneous rate decline solution is derived for a refractured horizontal well considering the fracture reorientation and fracture face damage, and a corresponding Blasingame-type rate decline solution is also deduced. A classic case in the literature as well a numerical simulation case was applied to verify and validate our proposed solution in Section 4 . In Section 5, the effects of reorientation fracture properties on the rate decline and cumulative production are deeply discussed, and a series of Blasingame-type rate decline curves and one field application of the proposed solution are presented too. Finally, we summarize our study in the last section.

\section{Physical Model}

Refracturing treatment is an economical way to improve well productivity for poorly or damaged fractured horizontal wells. Fracture reorientation and fracture face damage may occur during refracturing treatment. The newly formed fractures deviate from those fractures induced by the initial fracturing and propagate at different azimuthal angles and may undergo secondary reorientation and form non-coplanar reorientation fractures (Figure 1b, hydraulic fracture E). During this treatment, for those hydraulic fractures created by initial fracturing, some may further propagate and reorient, and also form reorientation fractures (Figure $1 b$, hydraulic fracture $\mathrm{B}^{\prime} / \mathrm{D}^{\prime}$ ), but some may lose seepage capacity permanently (Figure $1 b$, hydraulic fracture $A^{\prime} / C^{\prime}$ ). This study focuses on the influence of fracture reorientation and fracture face damage on the rate decline of refractured horizontal wells. Figure 2 presents the schematic of a refractured horizontal well model in a rectangular anisotropic reservoir. This horizontal wellbore is intercepted by multiple reorientation fractures, and each reorientation fracture is surrounded by a damaged zone. Note that for these reorientation fractures, some of them are formed by the continued propagation and reorientation of initial fracturing fractures, and others are entirely new fractures formed by refracturing treatment. For the simplification of the established model, the initial fracturing fractures that lose seepage capacity and do not contribute to well production (Figure $1 \mathrm{~b}$, hydraulic fracture $\mathrm{A}^{\prime} / \mathrm{C}^{\prime}$ ) are neglected in this model, and no longer appear in the schematic of this refractured well model. 


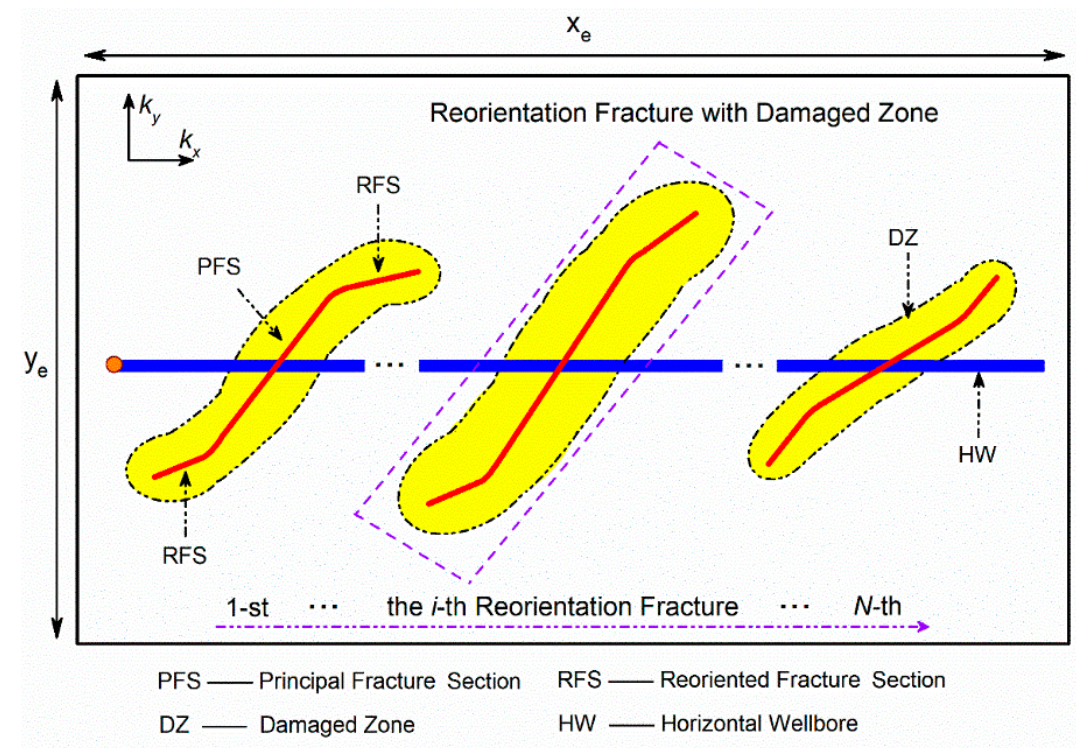

(a)

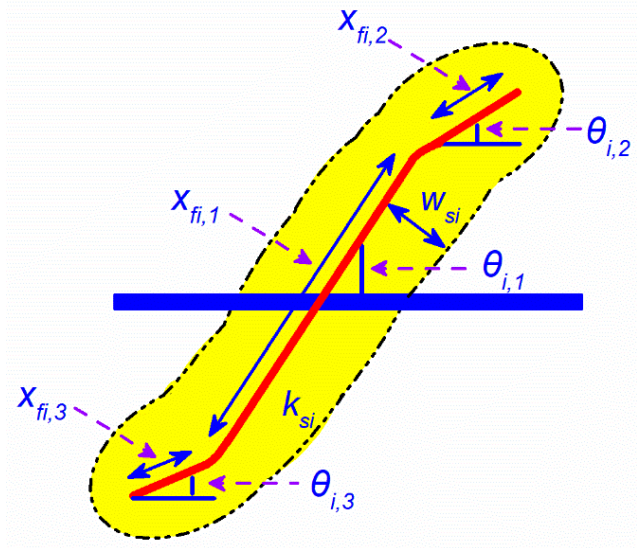

(b)

Figure 2. Schematic of a refractured horizontal well model intercepted by $N$ reorientation fractures with fracture face damage in a rectangular tight reservoir.(a) Map view of a refractured horizontal well in a rectangular anisotropic reservoir. (b) The properties of the $i$-th reorientation fracture with a damaged zone.

In order to successfully develop the rate decline solutions for this refractured horizontal well with fracture face damage, the basic assumptions of the physical model in this work are as follows:

(1) This is a closed, anisotropic, and rectangular reservoir with the side lengths $x_{e}$ and $y_{e}$, porosity $\phi$, and thickness $h$. Its $x$ - and $y$-axis permeabilities are $k_{x}$ and $k_{y}$ respectively, and the average reservoir permeability is $\bar{k}$, equal to $\sqrt{k_{x} k_{y}}$.

(2) The horizontal wellbore is parallel to the $x$-axis (the minimum horizontal principal stress direction), and is intercepted by $N$ reorientation fractures, including completely newly formed reorientation fractures and reorientation fractures transformed from initial fracturing fractures.

(3) All reorientation fractures are vertical and fully penetrate this tight formation. Each reorientation fracture reorients twice and is mainly composed of three sections, namely one principal fracture section and two reoriented fracture sections, shown in Figure 2.

(4) The permeability and porosity of all reorientation fractures are the same, $k_{f}$ and $\phi_{f}$, respectively. The width of every reorientation fracture $w_{f}$ cannot change with fracture reorientation, but the lengths of all reorientation fractures can be completely different. For the $i$-th reorientation fracture, its half-length is $x_{f i}$; the angle and length of its principal fracture section are $\theta_{i, 1}$ and $x_{f i, 1}$; the angles of its two reoriented fracture sections are $\theta_{i, 2}$ and $\theta_{i, 3}$, respectively and the corresponding lengths are $x_{f i, 2}$ and $x_{f i, 3}$, respectively.

(5) Every reorientation fracture is surrounded by a damage zone. The damaged zone of the $i$-th reorientation fracture has a reduced permeability $k_{s i}$ and width $w_{s i}$, shown as the yellow shaded areas in Figure 2.

(6) All production of fluid is via these $N$ reorientation fractures. No flow is allowed into reorientation fractures through fracture tips, and fluid flow in all fractures is linear and steady and obeys Darcy's law.

(7) Single-phase (tight oil or tight gas) and slightly compressible fluid (viscosity $\mu$, volume factor $B$, and compressibility $C_{t}$ ) flow occurs in this reservoir during well production, and all fluid first flows into reorientation fractures and then into the horizontal wellbore. The frictional resistance along the horizontal wellbore is not considered.

(8) All formation, fracture, and fluid properties are independent of pressure, and gravity effects are negligible.

(9) The initial pressure is uniform throughout this system, equal to $p_{\text {init }}$. 


\section{Mathematical Models}

To analyze the rate decline of a refractured horizontal well intercepted by multiple reorientation fractures with fracture face damage in a tight reservoir, a semi-analytical solution of the instantaneous rate decline and the pseudo-steady-state constant are derived, and then a Blasingame-type rate decline solution is deduced based on the proposed pseudosteady-state constant. For the sake of simplicity, to obtain the rate decline solutions, the important dimensionless variables used in this study are defined in Table 1.

Table 1. Definitions of dimensionless variables.

\begin{tabular}{|c|c|}
\hline Dimensionless Parameters & Definitions \\
\hline Reservoir pressure & $p_{D}=\frac{2 \pi \bar{k} h\left(p_{\text {init }}-p\right)}{Q \mu B}$ \\
\hline Average reservoir pressure & $p_{a v g D}=\frac{2 \pi \bar{k} h\left(p_{\text {init }}-p_{\text {avg }}\right)}{Q \mu B}$ \\
\hline Reorientation fracture pressure & $p_{f D}=\frac{2 \pi \bar{k} h\left(p_{\text {init }}-p_{f}\right)}{Q \mu B}$ \\
\hline Production time & $t_{D}=\frac{\bar{k} t}{\mu \phi C_{t} L_{R}^{2}}$ \\
\hline$x-, y$-coordinate & $x_{D}=\frac{x}{L_{R}}, y_{D}=\frac{y}{L_{R}}$ \\
\hline$x-, y$-coordinate of wellbore & $x_{w D}=\frac{x_{w}}{L_{R}}, y_{w D}=\frac{y_{w}}{L_{R}}$ \\
\hline Fracture spacing & $L_{f D}=\frac{L_{f}}{L_{R}}$ \\
\hline Fracture length ratio & $\alpha_{i}=\frac{x_{f i, 1}}{x_{f i, 2}+x_{f i, 3}}$ \\
\hline Permeability anisotropic factor & $\beta=\sqrt{\frac{k_{x}}{k_{y}}}$ \\
\hline Fracture face damage factor & $S_{f D i}=\frac{\pi w_{s i}}{2 L_{R}}\left(\frac{\bar{k}}{k_{s i}}-1\right)$ \\
\hline Reorientation fracture conductivity & $C_{f D}=\frac{k_{f} w_{f}}{\bar{k} L_{R}}$ \\
\hline Flow rate strength & $q_{f D}=\frac{q_{f} L_{R}}{Q}$ \\
\hline Flow rate of per unit reorientation fracture length & $q_{f w D}=\frac{q_{f w}}{Q}$ \\
\hline
\end{tabular}

\subsection{Reservoir Flow Model for a Refractured Horizontal Well}

$\mathrm{Wu}$ et al. [29] proposed a general point source function in a closed rectangular anisotropic reservoir. With the point source integration method, the solution of a line source with length $l_{D}$ in the Laplace domain was further obtained in this closed rectangular anisotropic reservoir,

$$
\begin{aligned}
& \widetilde{p}_{D}=\frac{\pi \beta}{x_{e D}[}\left[\begin{array}{c}
\int_{\Gamma} \widetilde{q}_{D i} \frac{\cosh \psi_{0}\left(y_{e D}-\left|y_{D} \pm y_{D p}\right|\right)}{\psi_{0} \sinh \psi_{0} y_{e D}} d l_{D} \\
+2 \int_{\Gamma} \widetilde{q}_{D i} \sum_{n=1}^{\infty} \frac{\cosh \psi_{n}\left(y_{e D}-\left|y_{D} \pm y_{D p}\right|\right)}{\psi_{n} \sinh \psi_{n} y_{e D}} \cos \left(\frac{n \pi x_{D}}{x_{e D}}\right) \cos \left(\frac{n \pi x_{D p}}{x_{e D}}\right) d l_{D}
\end{array}\right] \\
& \psi_{n}=\sqrt{\left(s \beta+\left(\beta \frac{n \pi}{x_{e D}}\right)^{2}\right)} n=0,1,2 \ldots
\end{aligned}
$$

where $\left(x_{D p}, y_{D p}\right)$ is the mid-point of the line source and $\left(x_{D}, y_{D}\right)$ is any point in the rectangular reservoir.

Note that Equation (1) is based on the assumption that the line source is parallel to the $x$-axis. However, reorientation fractures occurring in refracturing treatment mean that the line source in this study shows an arbitrary azimuthal angle $\theta$ (shown in Figure 3a). Fracture reorientation and permeability anisotropy cause the flow path of the fluid to bend 
when it flows from the reservoir outer boundary into these fractures (shown in Figure $3 b$ ). This flow phenomenon highlights the importance of constructing a line source solution integrating fracture reorientation and permeability anisotropy. To deal with the azimuthal angle existing in reorientation fractures, the following coordinate transformations were proposed [29],

$$
x_{D i}=x_{D p}+\sigma \cos \theta_{i} ; y_{D i}=y_{D p}+\sigma \sin \theta_{i}
$$

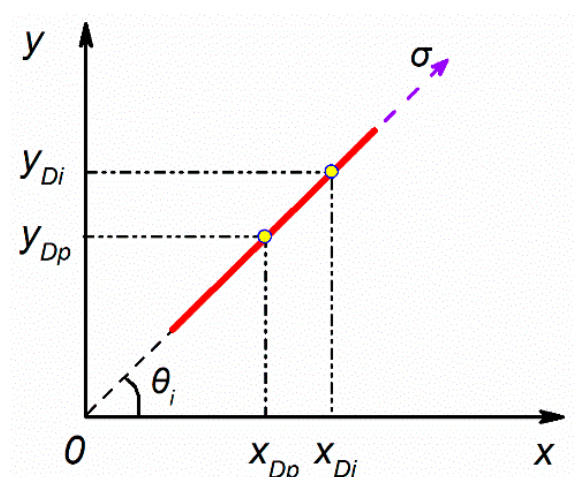

(a)

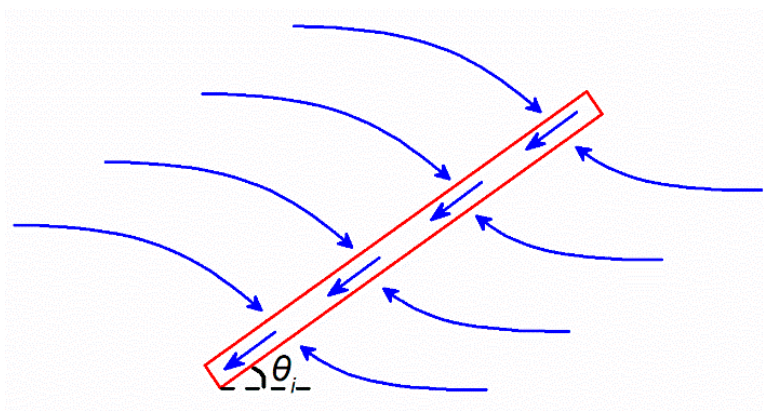

(b)

Figure 3. Coordinate transformation and schematic of the flow for the $i$-th line source. (a) The $i$-th line source. (b) Flow of the $i$-th line source.

Based on the above coordinate transformations, the solution of the line source with an arbitrary azimuthal angle in a closed rectangular anisotropic reservoir was obtained [29], which lays a solid foundation for the derivation of the reservoir solution of fluid flowing into reorientation fractures,

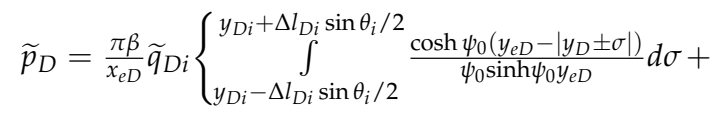

$$
\begin{aligned}
& \left.2 \int_{y_{D i}-\Delta l_{D i} \sin \theta_{i} / 2}^{y_{D i}+\Delta l_{D i} \sin \theta_{i} / 2} \sum_{n=1}^{\infty} \frac{\cosh \psi_{n}\left(y_{e D}-\left|y_{D} \pm \sigma\right|\right)}{\psi_{n} \sinh \psi_{n} y_{e D}} \cos \left(\frac{n \pi x_{D}}{x_{e D}}\right) \cos \frac{n \pi}{x_{e D}}\left[x_{D i}+\left(\sigma-y_{D i}\right) \cot \theta_{i}\right] d \sigma\right\}
\end{aligned}
$$

Then, all reorientation fractures in this refractured horizontal well were discretized and the $k$-th reorientation fracture was discretized into $N_{k}$ micro segments. Based on the pressure superposition principle, the reservoir solution for the proposed model in this study can be written as,

$$
\begin{aligned}
& \widetilde{p}_{D}=\frac{\pi \beta}{x_{e D}} \sum_{k=1}^{N} \sum_{i=1}^{N_{k}} \widetilde{q}_{D i}\left\{\begin{array}{l}
y_{D i}+\Delta l_{D i} \sin \theta_{i} / 2 \\
y_{D i}-\Delta l_{D i} \sin \theta_{i} / 2
\end{array} \frac{\cosh \psi_{0}\left(y_{e D}-\left|y_{D} \pm \sigma\right|\right)}{\psi_{0} \sinh \psi_{0} y_{e D}} d \sigma+\right. \\
& \left.2 \int_{y_{D i}-\Delta l_{D i} \sin \theta_{i} / 2}^{y_{D i}+\Delta l_{D i} \sin \theta_{i} / 2} \sum_{n=1}^{\infty} \frac{\cosh \psi_{n}\left(y_{e D}-\left|y_{D} \pm \sigma\right|\right)}{\psi_{n} \sinh \psi_{n} y_{e D}} \cos \left(\frac{n \pi x_{D}}{x_{e D}}\right) \cos \frac{n \pi}{x_{e D}}\left[x_{D i}+\left(\sigma-y_{D i}\right) \cot \theta_{i}\right] d \sigma\right\}
\end{aligned}
$$

\subsection{Reorientation Fracture Flow Model for a Refractured Horizontal Well}

For a horizontal well with multiple reorientation fractures, Xing et al. [35] proposed a flow equation in the Laplace domain for the $k$-th reorientation fracture (which was discretized into $N_{k}$ segments) by combining the nodal analysis with the material balance equation. Unfortunately, the flow equation proposed by Xing et al. [35] does not consider the influence of fracture face damage on the flow around the reorientation fractures. Here we establish a reorientation fracture flow equation with fracture face damage, and a further derivation of this equation is necessary. Figure 4 shows the flow in adjacent discrete fracture segments considering fracture face damage. 


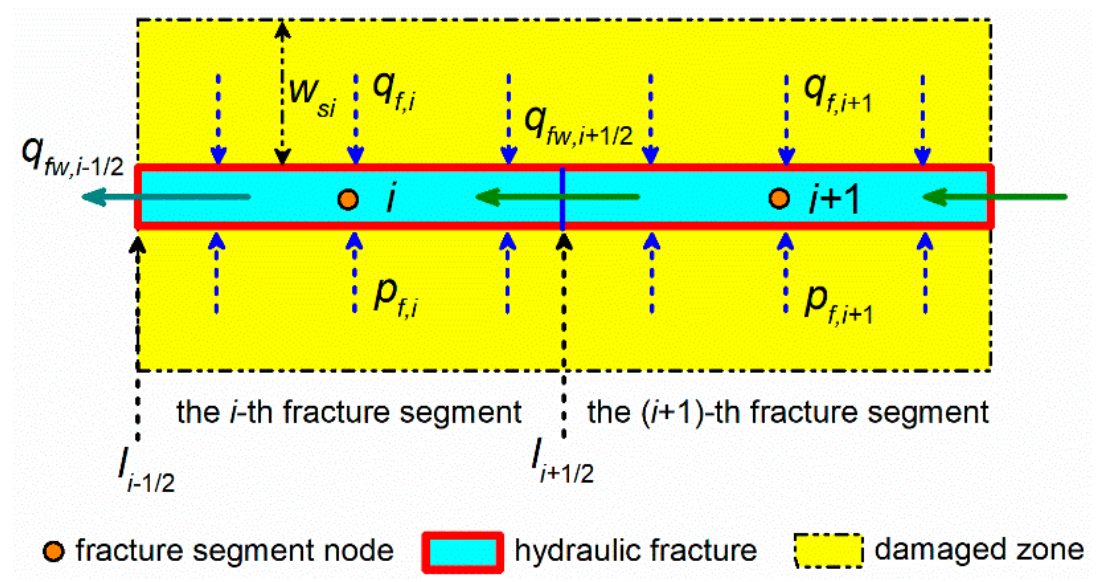

Figure 4. Flow in adjacent discrete fracture segments considering fracture face damage.

The pressure drop between the adjacent discrete fracture segments (the $i$-th and $(i+1)$-th fracture segments), without considering the influence of fracture face damage, can be written as,

$$
p_{f i+1}-p_{f i}=\int_{l_{i}}^{l_{i+0.5}} \frac{\mu B}{k_{f} w_{f} h} q_{f w i}(l, t) d l+\int_{l_{i+0.5}}^{l_{i+1}} \frac{\mu B}{k_{f} w_{f} h} q_{f w i+1}(l, t) d l
$$

According to the definition of fracture face damage proposed by Cinco-Ley and Samaniego [33], for the $i$-th discrete fracture segment, the total fracture pressure drop including the extra pressure drop caused by its damaged zone can be computed from,

$$
p_{i}=p_{f i}+\frac{q_{f i} \mu B w_{s i}}{4 h \bar{k}}\left(\frac{\bar{k}}{k_{s i}}-1\right)
$$

where $p_{i}$ represents the reservoir pressure near the $i$-th fracture segment and $p_{f i}$ represents the fracture face pressure of the $i$-th fracture segment. $w_{s i}$ and $k_{\mathrm{si}}$ are the width and the permeability of the damaged zone for the $i$-th fracture segment, respectively.

Substituting Equation (6) into Equation (5) yields the pressure drop equation between two adjacent fracture segments with fracture face damage,

$p_{i+1}-p_{i}=\frac{\mu B}{k_{f} w_{f} h}\left[\int_{l_{i}}^{l_{i+0.5}} q_{f w i}(l, t) d l+\int_{l_{i+0.5}}^{l_{i+1}} q_{f w i+1}(l, t) d l\right]+\frac{q_{f, i+1} \mu B w_{s, i+1}}{4 h \bar{k}}\left(\frac{\bar{k}}{k_{s, i+1}}-1\right)-\frac{q_{f, i} \mu B w_{s, i}}{4 h \bar{k}}\left(\frac{\bar{k}}{k_{s, i}}-1\right)$

Then the wellbore pressure can be obtained by employing the integration method from the first fracture segment for the $i$-th fracture segment,

$$
p_{i}-p_{w}=\frac{\mu B}{k_{f} w_{f} h}\left[\int_{l_{1-0.5}}^{l_{1+0.5}} q_{f w 1}(l, t) d l+\cdots+\int_{l_{(i-1)-0.5}}^{l_{(i-1)+0.5}} q_{f w(i-1)}(l, t) d l+\int_{l_{(i-1)+0.5}}^{l_{i}} q_{f w i}(l, t) d l\right]+\frac{q_{f, i} \mu B w_{s, i}}{4 h \bar{k}}\left(\frac{\bar{k}}{k_{s, i}}-1\right)
$$

Considering the mass balance for each fracture segment and each fracture node, the following flux relationship can be derived,

$$
\begin{gathered}
q_{f w i}=q_{f w(i-0.5)}-q_{f i}\left(l-l_{i-0.5}\right) \quad l_{i-0.5} \leq l \leq l_{i+0.5} \\
q_{f w, i-0.5}=\sum_{j=1}^{N_{I}}\left(q_{f j} \Delta l_{j}\right)-\sum_{j=1}^{i-1}\left(q_{f j} \Delta l_{j}\right)
\end{gathered}
$$


Combining Equations (8)-(10) yields the flow equation of one reorientation fracture,

$$
\begin{aligned}
p_{i}-p_{w}= & \frac{\mu B}{k_{f} w_{f} h}\left[\int_{l_{1-0.5}}^{l_{1+0.5}}\left[\sum_{j=1}^{N_{I}}\left(q_{f j} \Delta l_{j}\right)-q_{f 1}\left(l-l_{1-0.5}\right)\right] d l+\cdots+\int_{l_{(i-1)-0.5}}^{l_{(i-1)+0.5}}\left[\sum_{j=1}^{N_{I}}\left(q_{f j} \Delta l_{j}\right)-\sum_{j=1}^{i-2}\left(q_{f j} \Delta l_{j}\right)-q_{f i-1}\left(l-l_{i-1-0.5}\right)\right] d l\right] \\
& +\frac{\mu B}{k_{f} w_{f} h} \int_{l_{(i-1)+0.5}}^{l_{i}}\left[\sum_{j=1}^{N_{I}}\left(q_{f j} \Delta l_{j}\right)-\sum_{j=1}^{i-1}\left(q_{f j} \Delta l_{j}\right)-q_{f i}\left(l-l_{i-0.5}\right)\right] d l+\frac{q_{f, i} \mu B w_{s, i}}{4 h \bar{k}}\left(\frac{\bar{k}}{k_{s, i}}-1\right)
\end{aligned}
$$

Based on the dimensionless definitions in Table 1, Equation (11) can be rewritten in the dimensionless form,

$$
\begin{gathered}
p_{w D}-p_{D i}=\frac{2 \pi}{C_{f D}}\left[l_{D i} \sum_{j=1}^{N_{k}}\left(\Delta l_{D j} q_{f D j}\right)-\frac{\Delta l_{D i}^{2}}{8} q_{f D i}-\sum_{j=1}^{i-1}\left(\frac{\Delta l_{D j}}{2}+l_{D i}-\sum_{n=1}^{j} \Delta l_{D n}\right) \Delta l_{D j} q_{f D j}\right]+q_{f D i} S_{f D i} \\
\text { where } S_{f D i}=\frac{\pi w_{s i}}{2 L_{R}}\left(\frac{\bar{k}}{k_{s i}}-1\right) .
\end{gathered}
$$

Further, in the Laplace domain, for the $i$-th reorientation fracture, the flow solution with fracture face damage can be obtained,

$$
\widetilde{p}_{w D}-\widetilde{p}_{D i}=\frac{2 \pi}{C_{f D}}\left[l_{D i} \sum_{j=1}^{N_{k}}\left(\Delta l_{D j} \widetilde{q}_{f D j}\right)-\frac{\Delta l_{D i}^{2}}{8} \widetilde{q}_{f D i}-\sum_{j=1}^{i-1}\left(\frac{\Delta l_{D j}}{2}+l_{D i}-\sum_{n=1}^{j} \Delta l_{D n}\right) \Delta l_{D j} \widetilde{q}_{f D j}\right]+\widetilde{q}_{f D, i} S_{f D i}
$$

To the best of our knowledge, Equation (13) is a new flow equation to describe the flow behavior of a reorientation fracture with fracture face damage.

\subsection{Traditional Rate Decline Solution for a Refractured Horizontal Well}

In this work, we do not consider wellbore friction and thus there is no pressure drop along the horizontal wellbore. Under the circumstances, the following wellbore pressure equation can be obtained for $N$ reorientation fractures,

$$
\widetilde{p}_{w D k}=\widetilde{p}_{w D}, k=1,2, \cdots N
$$

where $\widetilde{p}_{w D k}$ represents the dimensionless pressure at the intersection of the $k$-th reorientation fracture and the horizontal wellbore.

Considering the continuity conditions along all reorientation fracture faces, the following flux equations can be yielded,

$$
\widetilde{q}_{D k, i}=\widetilde{q}_{f D k, i}, i=1,2, \cdots \sum_{k=1}^{N} \sum_{m=1}^{N_{k}} m
$$

Further, the production rate of the refractured horizontal well is equal to the sum of the flow rates of all reorientation fractures, and thus the following productivity equation can be established in the Laplace domain,

$$
\sum_{k=1}^{N} \sum_{m=1}^{N_{k}}\left(\Delta l_{D k, m} \widetilde{q}_{f D k, m}\right)=\frac{1}{s}
$$

Finally, Equations (4) and (13)-(16) compose a linear matrix system, which has $1+\sum_{k=1}^{N} \sum_{m=1}^{N_{k}} m$ equations and $1+\sum_{k=1}^{N} \sum_{m=1}^{N_{k}} m$ unknowns,

$$
\mathbf{A}\left(1+\sum_{k=1}^{N} \sum_{m=1}^{N_{k}} m\right) \times\left(1+\sum_{k=1}^{N} \sum_{m=1}^{N_{k}} m\right)^{\mathbf{X}} 1 \times\left(1+\sum_{k=1}^{N} \sum_{m=1}^{N_{k}} m\right)=\mathbf{b}\left(1+\sum_{k=1}^{N} \sum_{m=1}^{N_{k}} m\right) \times 1
$$


This matrix system can be easily solved by the Gaussian elimination method, and then in the Laplace domain, the dimensionless transient wellbore pressure of a horizontal well intercepted by $N$ reorientation fractures with fracture face damage can be obtained at a constant wellbore flow rate.

According to the Duhamel principle [36,37], there is an internal relationship between the instantaneous rate at a constant wellbore pressure and the transient pressure at a constant rate in the Laplace domain,

$$
\begin{gathered}
s^{2} \widetilde{q}_{D}(s) \widetilde{p}_{w D}=1 \\
s^{2} \widetilde{q}_{C D}(s) \widetilde{q}_{D}(s)=\frac{1}{s}
\end{gathered}
$$

Depending on the numerical inversion algorithm presented by Stehfest [38], Equations (18) and (19) can be solved, and then the dimensionless instantaneous rate decline and the cumulative production in the real-time domain can be obtained.

\subsection{Blasingame Rate Decline Solution Based on Semi-Analytical Pseudo-Steady-State Constant}

Fetkovich [15] presented the basic rate decline for type curves as,

$$
\begin{aligned}
q_{D d} & =q_{D} b_{D p s s} \\
t_{D d} & =\frac{2 \pi t_{D A}}{b_{D p s s}}
\end{aligned}
$$

where $b_{D p s s}$ and $t_{D A}$ represent the dimensionless pseudo-steady-state constant and dimensionless material balance time, respectively.

In order to reduce the multiple solutions and errors that exist in well test inversion, Blasingame et al. [17] proposed the integral average method, and the auxiliary variables in this method for Blasingame type curves are given by,

(1) Rate integral function: $q_{D d i}$

$$
q_{D d i}=\frac{\int_{0}^{t_{D d}} q_{D d}(\sigma) d \sigma}{t_{D d}}
$$

(2) Rate integral-derivative function: $q_{\text {Ddid }}$

$$
q_{D d i d}=-\frac{d q_{D d i}}{d \ln t_{D d}}=-t_{D d} \frac{d q_{D d i}}{d t_{D d}}=q_{D d i}-q_{D d}
$$

From Equations (20)-(23), the key to establishing Blasingame-type rate decline curves lies in the acquisition of the dimensionless pseudo-steady-state constant $b_{D p s s}$. Many solutions have been reported to obtain this parameter [34,39-41]. However, to our best knowledge, there is no report to calculate the dimensionless pseudo-steady-state constant of a refractured horizontal well in a rectangular tight reservoir.

The dimensionless pressure at any point for a rectangular anisotropic reservoir in the pseudo-steady-state regime can be expressed as [30],

$$
p_{D i}=p_{a v g D}+\sum_{k=1}^{N} \sum_{j=1}^{N_{k}} q_{D k, j} F_{D i, j}\left(x_{D i}, y_{D i}, x_{D j}, y_{D j}, \beta\right) k=1,2 \ldots N i=1,2 \ldots N_{k}
$$

where $F_{D}$ is the dimensionless influence function. 
According to the continuity conditions (Equation (15)), in the real-time domain, the continuous flux equations along all reorientation fracture faces can be written as,

$$
q_{D k, i}=q_{f D k, i}, i=1,2, \cdots, \sum_{k=1}^{N} \sum_{m=1}^{N_{k}} m
$$

Combining Equations (12), (24), and (25) yields,

$$
\begin{aligned}
p_{w D D}= & p_{a v g D}+\sum_{k=1}^{N} \sum_{j=1}^{N_{k}} q_{f D k, j} F_{D i, j}\left(x_{D i}, y_{D i}, x_{D j}, y_{D j}, \beta\right)+q_{f D i} S_{f D i}+ \\
& \frac{2 \pi}{F_{c D}}\left[l_{D i} \sum_{j=1}^{N_{k}}\left(\Delta l_{D j} q_{f D j}\right)-\frac{\Delta l_{D i}^{2}}{8} q_{f D i}-\sum_{j=1}^{i-1}\left(\frac{\Delta l_{D j}}{2}+l_{D i}-\sum_{n=1}^{j} \Delta l_{D n}\right) \Delta l_{D j} q_{f D j}\right]
\end{aligned}
$$

According to the research of Pratikno et al. [39], the wellbore pressure $p_{w D}$ and the pseudo-steady-state constant $b_{D p s s}$ have the following relationship in the pseudo-steadystate regime,

$$
p_{w D}=p_{a v g D}+b_{D p s s}
$$

Combining Equations (26) and (27), we can obtain $\sum_{k=1}^{N} \sum_{m=1}^{N_{k}} m$ equations with $1+\sum_{k=1}^{N} \sum_{m=1}^{N_{k}} m$ unknowns,

$$
\mathbf{A}\left(\sum_{k=1}^{N} \sum_{m=1}^{N_{k}} m\right) \times\left(1+\sum_{k=1}^{N} \sum_{m=1}^{N_{k}} m\right) \mathbf{q}_{\mathbf{f D}}\left[1 \times\left(1+\sum_{k=1}^{N} \sum_{m=1}^{N_{k}} m\right)\right]=\mathbf{b}_{\text {Dpss }}
$$

Similarly, in the real-time domain, the total rate satisfies the following equation,

$$
\sum_{k=1}^{N} \sum_{j=1}^{N_{k}} \Delta l_{D k, j} q_{f D k, j}=1
$$

A matrix system of $\left(1+\sum_{k=1}^{N} \sum_{m=1}^{N_{k}} m\right) \times\left(1+\sum_{k=1}^{N} \sum_{m=1}^{N_{k}} m\right)$ can be yielded when combining Equations (28) and (29),

$$
\left(\begin{array}{cc}
\mathbf{A} & -1 \\
\Delta \mathbf{l}_{\mathrm{D}} & 0
\end{array}\right)\left(\begin{array}{c}
\mathbf{q}_{\mathrm{fD}} \\
\mathbf{b}_{\mathrm{Dpss}}
\end{array}\right)=\left(\begin{array}{l}
0 \\
1
\end{array}\right)
$$

Obviously, the dimensionless pseudo-steady-state constant $b_{D p s s}$ can be obtained by solving Equation (30) with the Gauss elimination method. Substituting the pseudosteady-state constant into Equations (20) and (21) produces the basic rate decline curves. Finally, depending on the semi-analytical pseudo-steady-state constant, Blasingame-type rate decline curves can also be calculated and plotted.

\section{Verification and Validation of Traditional Rate Decline Solution}

To the best of our knowledge, there are no reports on the rate decline solution of a refractured horizontal well intercepted by multiple reorientation fractures with fracture face damage. In this section, a simplified model in the literature was first used to verify the rate decline solution presented in this work, and then the production rate of multiple reorientation fractures with a constant fracture skin factor computed from commercial software (Eclipse) was further used to validate the accuracy and reliability of our proposed rate decline solution.

Luo et al. [42] developed a semi-analytical model to analyze the transient rate response for a vertical well intercepted by a dynamic conductivity fracture with pressure-dependent permeability. When we consider one reorientation fracture without fracture face damage in 
our model and assume the corresponding azimuthal angles of the principal fracture section and reoriented fracture sections are equal to $0^{\circ}$ (parallel to the $x$-axis), our model can be regressed to Luo et al.'s model according to the application of the source function theory. Figure 5 shows the comparison of the results in this work with the solution presented by Luo et al. under different fracture conductivities $\left(C_{f D}=1,10,100\right)$. Obviously, our calculated rate decline agrees well with Luo et al.'s solution for the entire flow regimes, which verifies the accuracy of our model.

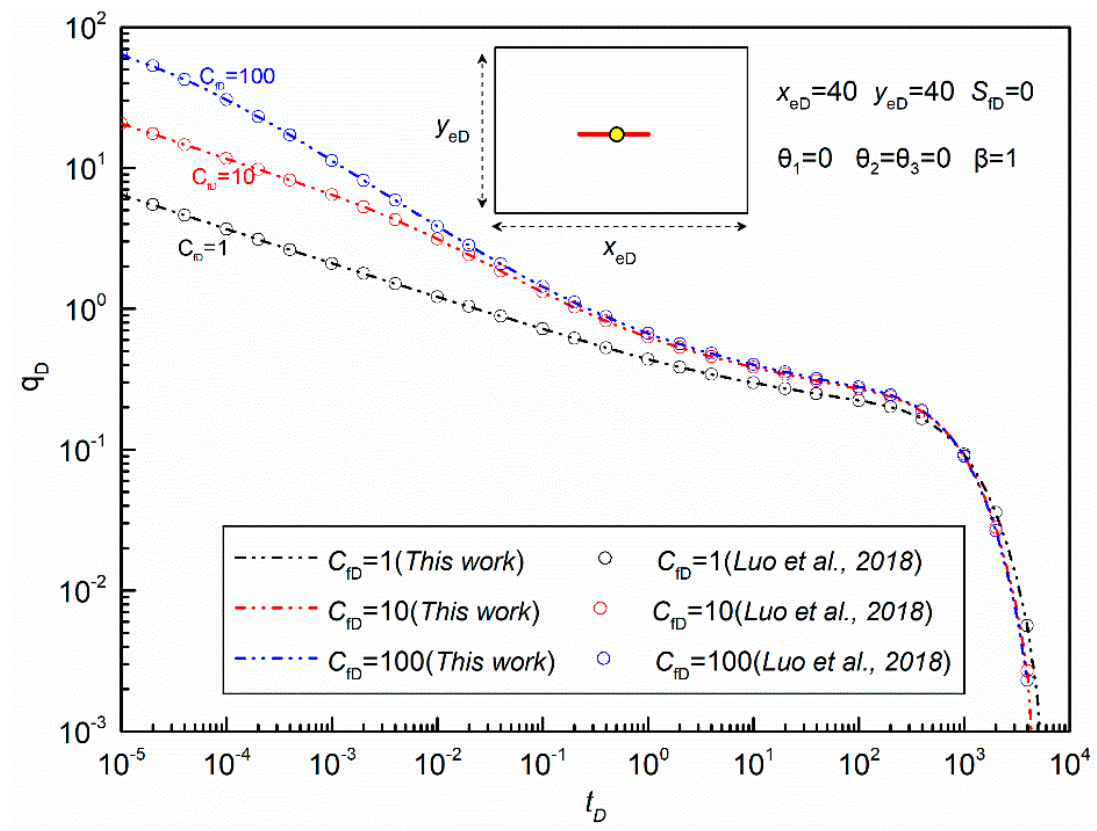

Figure 5. Comparison of the results in this work with the solution presented by Luo et al. [42].

Eclipse is a widely used reservoir numerical simulation software. Here we use this software to simulate the rate decline of a horizontal well intercepted by three reorientation fractures with fracture face damage in a rectangular anisotropic reservoir. The model we built in this study is for single-phase fluid, and thus the $100 \%$ saturated oil phase is set in the numerical simulation model. In order to simplify the validation, we assume three reorientation fractures have the same properties and are evenly distributed in parallel along the horizontal wellbore (Figure 6). In order to accurately reflect the properties of reorientation fractures with fracture face damage, a zigzag fracture pattern by local grid refinement (LGR) is used to approximately replace three reorientation fractures. The permeability of these refined grids is $1030 \times 10^{-3} \mu \mathrm{m}^{2}$, and the permeability of the grids adjacent to these fracture grids is $0.0005 \times 10^{-3} \mu \mathrm{m}^{2}$ (corresponding to damaged zone permeability). The relevant parameters used for numerical simulation are presented in Table 2. Figure 6 compares the results from this work and those computed from Eclipse. The comparison suggests that the results calculated from our model are highly consistent with the results from the commercial software, which further validates the accuracy and reliability of the model proposed in this study. 


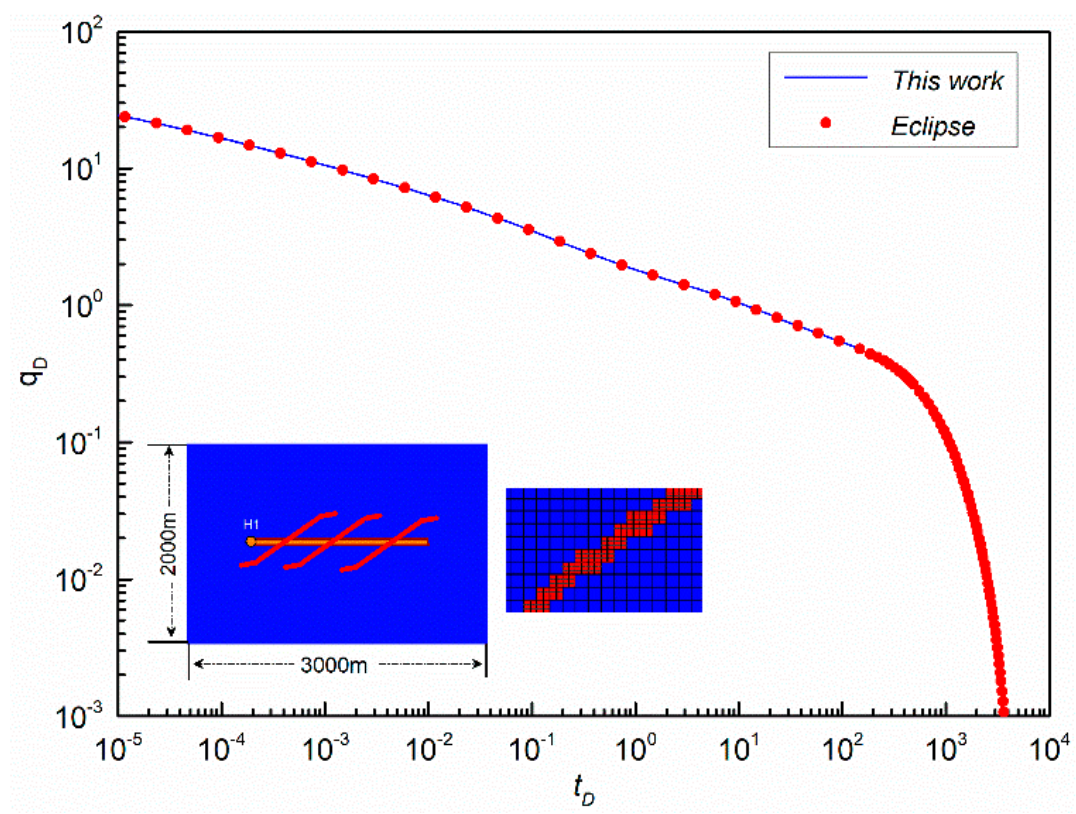

Figure 6. Comparison of the results in this work with the results from the commercial software.

Table 2. The parameters used in the numerical simulator (Eclipse).

\begin{tabular}{cc}
\hline Basic Model Parameters & Value \\
\hline Reservoir drainage area, $\mathrm{m}^{2}$ & $3000 \times 2000$ \\
Reservoir porosity, $\%$ & 8 \\
Permeability in the $x$-axis, $10^{-3} \mu \mathrm{m}^{2}$ & 0.2 \\
Permeability in the $y$-axis, $10^{-3} \mu \mathrm{m}^{2}$ & 0.05 \\
Tight oil viscosity, $\mathrm{mPa} \cdot \mathrm{s}$ & 0.8 \\
Tight oil density, $\mathrm{g} / \mathrm{cm}^{3}$ & 0.832 \\
Net thickness, $\mathrm{m}$ & 10 \\
Wellbore inside diameter, $\mathrm{m}$ & 0.18 \\
Initial reservoir pressure, $\mathrm{MPa}$ & 20 \\
Bottomhole flow pressure, $\mathrm{MPa}$ & 8 \\
Volume factor, $\mathrm{m}^{3} / \mathrm{m}^{3}$ & 1.1 \\
Total compressibility, $10^{-3} \mathrm{MPa}-1$ & 4 \\
Horizontal wellbore length, $\mathrm{m}$ & 1200 \\
Fracture number, integer & 3 \\
Fracture spacing, $\mathrm{m}$ & 500 \\
Half-length of one fracture, $\mathrm{m}$ & 50 \\
Length of principal fracture section, $\mathrm{m}$ & 75 \\
Length of reoriented fracture section, $\mathrm{m}$ & 12.5 \\
Angle of principal fracture section, degree & 60 \\
Angle of reoriented fracture section, degree & 45 \\
Fracture width, $\mathrm{m}$ & 0.015 \\
Fracture permeability, $10^{-3} \mu \mathrm{m}^{2}$ & 1030 \\
Width of damaged zone, $\mathrm{m}$ & 0.016 \\
Permeability in damaged zone, $10^{-3} \mu \mathrm{m}^{2}$ & 0.0005 \\
\hline
\end{tabular}

\section{Results and Discussion}

Based on the traditional rate decline solution, single-factor sensitivity analysis and multifactor sensitivity analysis of the rate decline of a refractured horizontal well were conducted by plotting various rate decline curves in this section. The effects of reorientation fracture properties on the instantaneous rate decline and cumulative production, including fracture face damage, the fracture angle, fracture rotation, the fracture length ratio, fracture spacing, and the fracture number, were discussed in detail. A series of Blasingame-type rate decline curves were also presented for different reorientation fracture properties. With 
these traditional or Blasingame rate decline curves, we can gain insight into how the production of a refractured horizontal well with fracture face damage in tight reservoirs changes. Finally, curve fitting for a field case was conducted to estimate fracture parameters, which shows the excellent application of our proposed model in identifying reorientation fracture properties and evaluating the post-refracturing performance.

The superposition of the influence of various reorientation fracture properties on the rate decline may mask the influence law of a single factor. In order to reduce the masking effect of fracture property differences and highlight the influence law of a single factor, in these discussions, assume that all reorientation fractures have the same properties and are distributed in parallel along the horizontal wellbore. In fact, all reorientation fractures in our proposed model can have completely different properties and can also be deployed arbitrarily, which are the advantages and innovations of this model. These plotted rate decline curves are helpful to deeply understand the production variation law of refractured horizontal wells and lay a foundation for well test inversion and fracture parameter identification. It should be noted that the following sensitivity analysis results are based on the basic parameter values in Table 3 . If the values of basic parameters change greatly, the analysis results in this paper may be not applicable.

Table 3. Basic values of parameters used in single-factor sensitivity analysis $(i=1,2,3)$.

\begin{tabular}{ccccccccccc}
\hline $\mathbf{x}_{\mathrm{eD}}$ & $\mathbf{y}_{\mathrm{eD}}$ & $\mathbf{F N}$ & $\theta_{\mathrm{i}, \mathbf{1}}$ & $\theta_{\mathrm{i}, \mathbf{2}}$ & $\theta_{\mathrm{i}, \mathbf{3}}$ & $\mathrm{C}_{\mathrm{fD}}$ & $\mathbf{L}_{\mathrm{fD}}$ & $\mathbf{S}_{\mathrm{fDi}}$ & $\boldsymbol{\alpha}_{\mathbf{i}}$ & $\boldsymbol{\beta}$ \\
\hline 60 & 40 & 3 & $\pi / 3$ & $\pi / 4$ & $\pi / 4$ & $\pi$ & 10 & 0.1 & 3 & 2 \\
\hline
\end{tabular}

\subsection{Single Factor Sensitivity Analysis of Traditional Rate Decline and Cumulative Production}

Single-factor sensitivity analysis is carried out using the control variable method. The basic values of the parameters used to calculate the instantaneous rate and cumulative production are presented in Table 3. When analyzing the influence of one factor, the values of other factors remain unchanged and the rate decline curves are drawn under different values of the factor to be studied.

\subsubsection{Fracture Face Damage}

Fracture face damage is one focus of this study. To examine the effect of fracture face damage on the production of a refractured horizontal well, a series of rate-decline and cumulative-production curves were plotted for different fracture face damage values $\left(S_{f D i}=0,0.05,0.1,0.2\right)$, as shown in Figure 7.

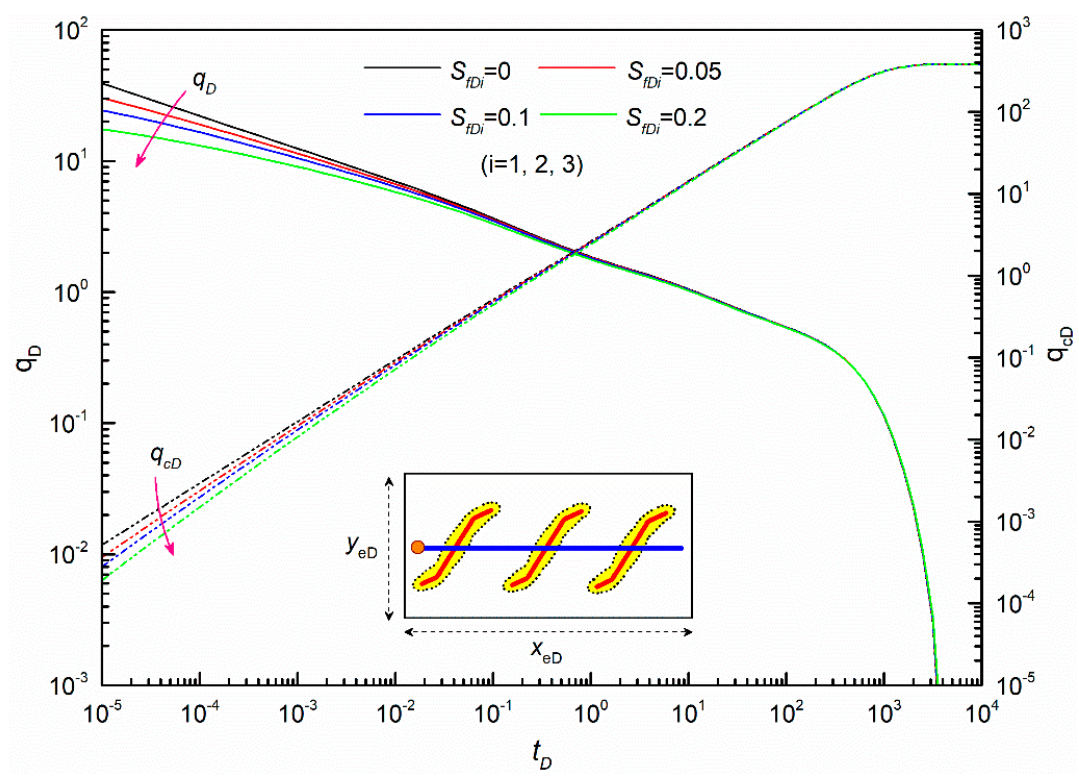

Figure 7. Effect of fracture face damage on the rate decline and cumulative production. 
Figure 7 illustrates that fracture face damage mainly affects the early flow period $\left(t_{D} \leq 10^{-1}\right)$ and has nearly no effect on the middle and late flow periods, and both the instantaneous rate and cumulative production decrease with the increase in fracture face damage in the early flow period. This characteristic can be ascribed to the fact that the early flow period is dominated by the newly formed reorientation fractures and the increase in fracture face damage factor results in an increase in flow resistance around the fractures, and thus the negative correlation between the production rate and fracture face damage appears in the early flow period. Meanwhile, another characteristic can be observed in Figure 7, whereby the more serious the fracture face damage is, the longer the early flow period affected by fracture face damage lasts, which can be interpreted as the fracture damage zone becoming thicker or the permeability near the fracture becoming worse with the increase in fracture face damage, and thus the early flow period affected by fracture face damage lasts longer. In the late flow period $\left(t_{D}>10^{3}\right)$, the instantaneous rate and cumulative production under different fracture face damage values are similar. This feature is determined by the boundary-dominant flow of the closed reservoir, and the insufficient fluid supply in this period weakens the effect of fracture face damage.

\subsubsection{Reorientation Fracture Angle}

The angles of the principal fracture section and reoriented fracture section are two key parameters to characterize the properties of reorientation fractures. Considering the potential impact of the matching relationship between permeability anisotropy and the fracture angle on well production, the permeability anisotropic factor is assumed to be constant $(\beta=2)$ when detecting the influence of the reorientation fracture angle on the rate decline. Figures 8 and 9 present the rate-decline and cumulative-production curves with varied angles of the principal fracture section and reoriented fracture section, respectively.

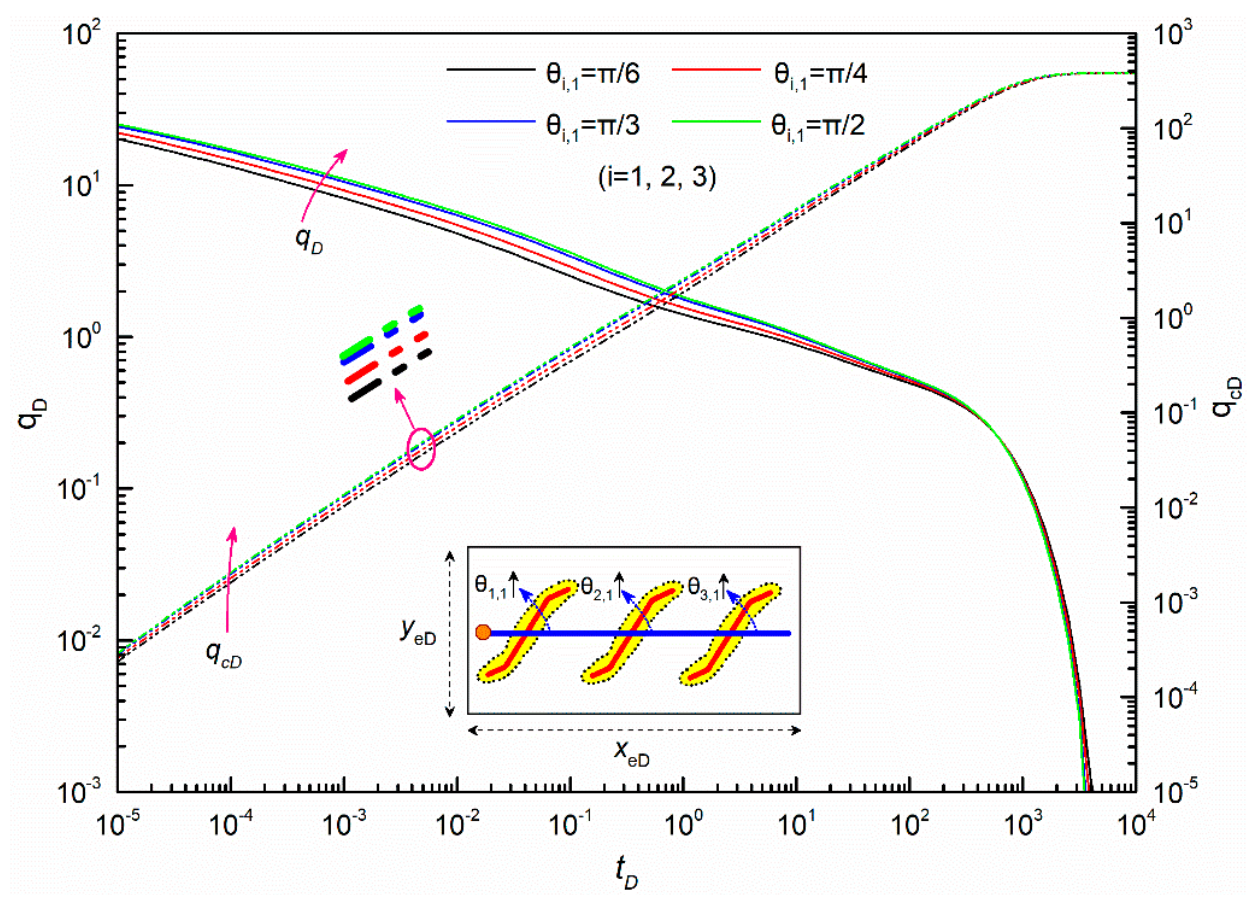

Figure 8. Effect of principal fracture section angle on the rate decline and cumulative production. 


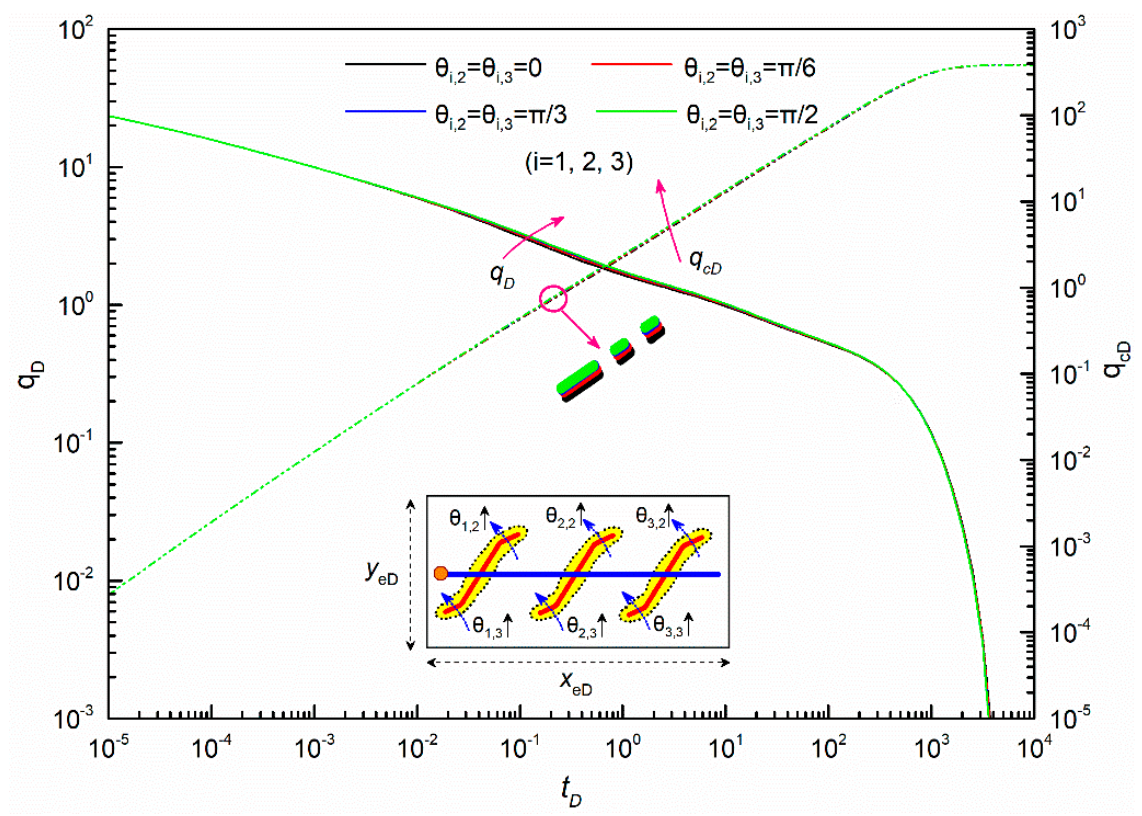

Figure 9. Effect of reoriented fracture section angle on the rate decline and cumulative production.

As shown in Figure 8, the production rate in the early and middle flow periods increases with the increase in the principal fracture section angle while the rate-decline and cumulative-production curves tend to coincide with each other in the late flow period $\left(t_{D} \geq 10^{3}\right)$, which is dominated by the closed boundary effect. This phenomenon can be explained by the fact that, for a fixed permeability anisotropic factor $(\beta=2)$, as the angle between the reorientation fracture faces and the direction of minimum seepage resistance ( $x$-axis) becomes larger, the controlled seepage area of each reorientation fracture expands, and the corresponding flow resistance also becomes weaker. When the principal fracture section angle increases to some degree, the transient rate shows a minor change. For example, the rate-decline and cumulative-production curves for $\theta_{i, 1}=\pi / 3$ (blue line) and $\theta_{i, 1}=\pi / 2$ (green line) almost overlap together, as demonstrated in Figure 8. This phenomenon indicates that there is an optimal relationship between principal fracture section angle and reservoir permeability anisotropy to achieve efficient and economical development in the early and middle flow periods.

Different from the effect of the principal fracture section angle on the rate decline and cumulative production, the reoriented fracture section angle only affects the middle flow period. As presented in Figure 9, the production rate in the middle flow period is directly proportional to the reorientated fracture section angle. However, the effect of the reoriented fracture section angle on the transient rate is not as sensitive as that of the principal fracture section angle, referring to the evidence that the rate-decline curves tend to overlap for different reoriented fracture section angles. The obvious difference in the effect of the principal fracture section angle and the reoriented fracture section angle on well production is due to the fact that all principal fracture sections are longer than these reoriented fracture sections and can affect a larger seepage area.

\subsubsection{Fracture Rotation}

Generally, the angle between the reorientation fracture face and the horizontal wellbore is dependent on the in-situ stress change before and after the initial fracturing treatment. In order to further investigate the effect of the reorientation fracture angle on well production, we maintained the intersection angle between the principal fracture section and the reoriented fracture section at a constant degree $\left(\theta_{i, 1}-\theta_{i, 2}=\pi / 12\right.$ and $\left.\theta_{i, 1}-\theta_{i, 3}=\pi / 12\right)$ and discuss the production rate change caused by reorientation fracture rotation. Figure 10 displays the rate-decline and cumulative-production curves under different fracture rotations $\left(\theta_{i, 1}=\pi / 6, \pi / 4, \pi / 3,5 \pi / 12, \pi / 2\right)$. It can be observed in Figure 10 that reorientation 
fracture rotation mainly affects the early and middle flow periods, which is similar to the influence of the principal fracture section angle. A larger fracture rotation can expand the seepage area affected by reorientation fractures, leading to a higher production rate. Meanwhile, for this anisotropic reservoir, when these reorientation fractures rotate to a certain degree, the seepage area affected by reorientation fractures reach a maximum value and then the increase in the production rate slows down, which coincides with the rate decline curves at $\theta_{i, 1}=5 \pi / 12$ (violet solid line) and $\theta_{i, 1}=\pi / 2$ (green solid line) as shown in Figure 10.

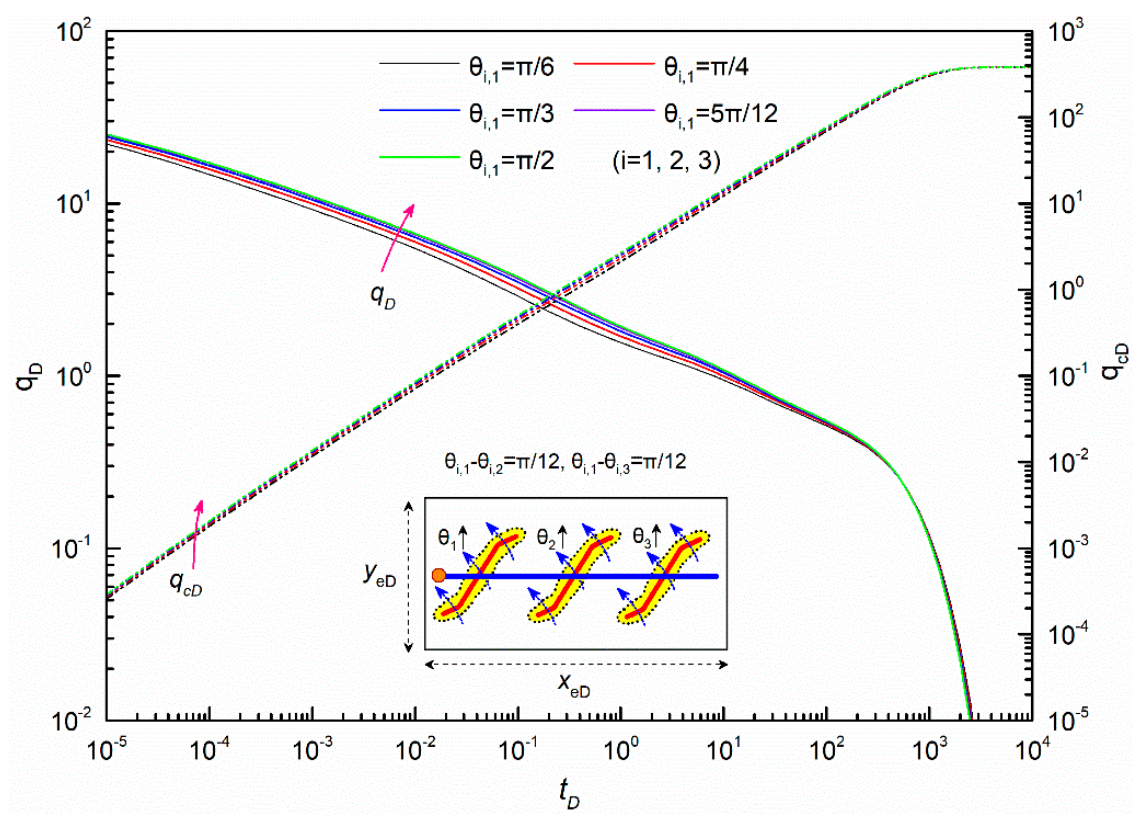

Figure 10. Effect of fracture rotation on the rate decline and cumulative production.

Comparing Figures 8-10, it can be concluded that the principal fracture section angle has a greater impact on well production in the early and middle flow periods. In the late flow period, all the instantaneous rate curves for different fracture angles almost overlap, as do the cumulative production curves. In total, the low fluid supply under the boundary-dominant flow weakens the influence of the reorientation fracture angle on late-stage well production.

\subsubsection{Fracture Length Ratio}

Similar to the impact of the reorientation fracture angle on the transient rate and cumulative production, the lengths of the principal fracture section and reoriented fracture section are other non-negligible fracture properties affecting well production. In the derivation of the rate decline solutions, we maintained the total length of each reorientation fracture unchanged and introduced the fracture length ratio (which is the length ratio of one principal fracture section to two reoriented fracture sections, $\left.\alpha_{i}=x_{f i, 1} /\left(x_{f i, 2}+x_{f i, 3}\right)\right)$ as an evaluation parameter to investigate the effect of reorientation fracture length on well production. Figure 11 demonstrates the effect of the fracture length ratio on the rate decline and cumulative production $\left(\alpha_{i}=3 / 1,2 / 1,1 / 1,1 / 2,1 / 3\right)$.

Obviously, as shown in Figure 11, the fracture length ratio mainly affects the middle flow period, and a weak reduction of the transient rate and cumulative production can be observed with the decrease in the fracture length ratio in this period, which can be ascribed to the fact that a lower fracture length ratio represents a shorter principal fracture section and also corresponds to a narrower favorable seepage area. Compared with the other reorientation fracture properties, the influence of the fracture length ratio on well production is rather weak. This comparison result is based on the basic parameter values given in Table 3. However, under the conditions of strong permeability anisotropy, a large total length, and a favorable angle of reoriented fracture sections, the fracture length ratio 
will have a greater impact on well production and cannot be neglected. For these kinds of tight reservoirs, the optimization of the fracture length ratio before refracturing treatment is still necessary to achieve high productivity.

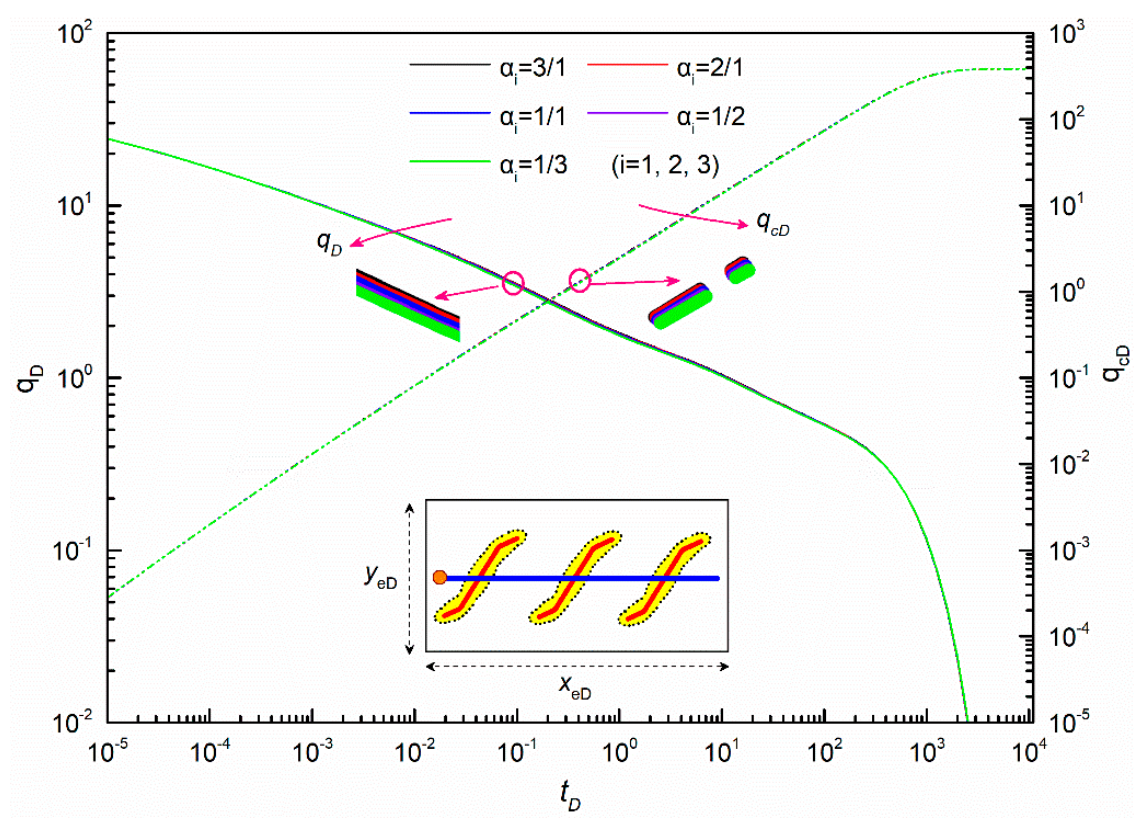

Figure 11. Effect of fracture length ratio on the rate decline and cumulative production.

\subsubsection{Fracture Spacing}

For a refractured horizontal well with multiple reorientation fractures, fracture spacing is a significant factor affecting its production. In this sensitivity analysis, the fracture number is set to 3 and all fractures have the same properties. Figure 12 presents the effect of fracture spacing on the instantaneous rate and cumulative production $\left(L_{f D}=5,10,15,20\right)$.

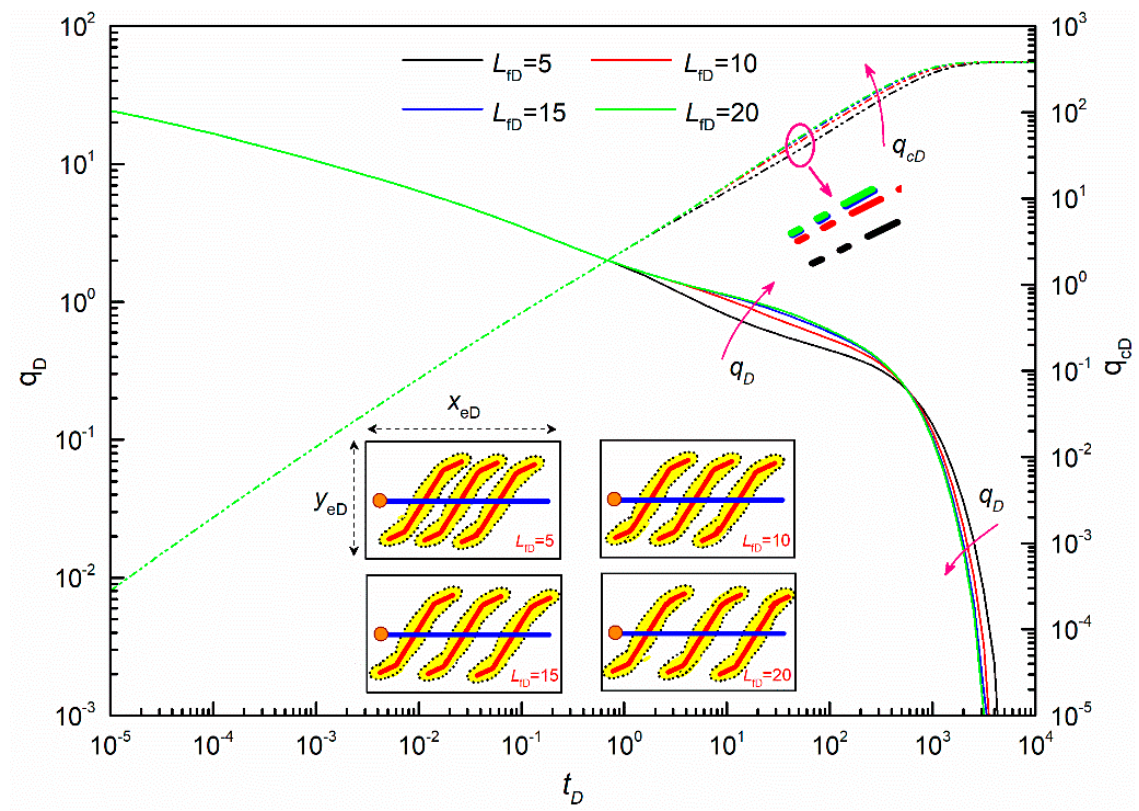

Figure 12. Effect of fracture spacing on the rate decline and cumulative production.

As presented in Figure 12, the production rate under wide fracture spacing is higher than that under narrow fracture spacing in the middle flow period, implying that wider fracture spacing is conductive to improving well production in this period. This phenomenon can be interpreted as, for a fixed seepage area, the interferences between the 
adjacent fractures become weak and fluid flow channels also become smooth when fracture spacing increases to some degree. This result is obtained without considering the fracture number; however, it is unwise to ignore the influence of a lower fracture number in order to pursue wider fracture spacing in the field. Interestingly, the transient rate in the late flow period is inversely proportional to fracture spacing, which can be explained by the fact that when the refractured horizontal well has wider fracture spacing, the pressure drop wave reaches the outer boundary quicker and the horizontal well also feels the influence of the outer boundary earlier, leading to a lower instantaneous production rate in the late flow period.

\subsubsection{Reorientation Fracture Number}

Generally, the productivities of multi-fractured horizontal wells are largely determined by the fracture number created by hydraulic fracturing. Therefore, analyzing the effect of the reorientation fracture number on refractured horizontal well production is significant. Figure 13 demonstrates the effect of the reorientation fracture number on the rate decline and cumulative production $(F N=3,5,7,9)$. All reorientation fractures have the same properties and are deployed in parallel from the midpoint of the horizontal wellbore to both ends with a constant dimensionless spacing of 10 . In order to highlight the contrast effect, we maintained the total length and total area of fractures equal for all cases.

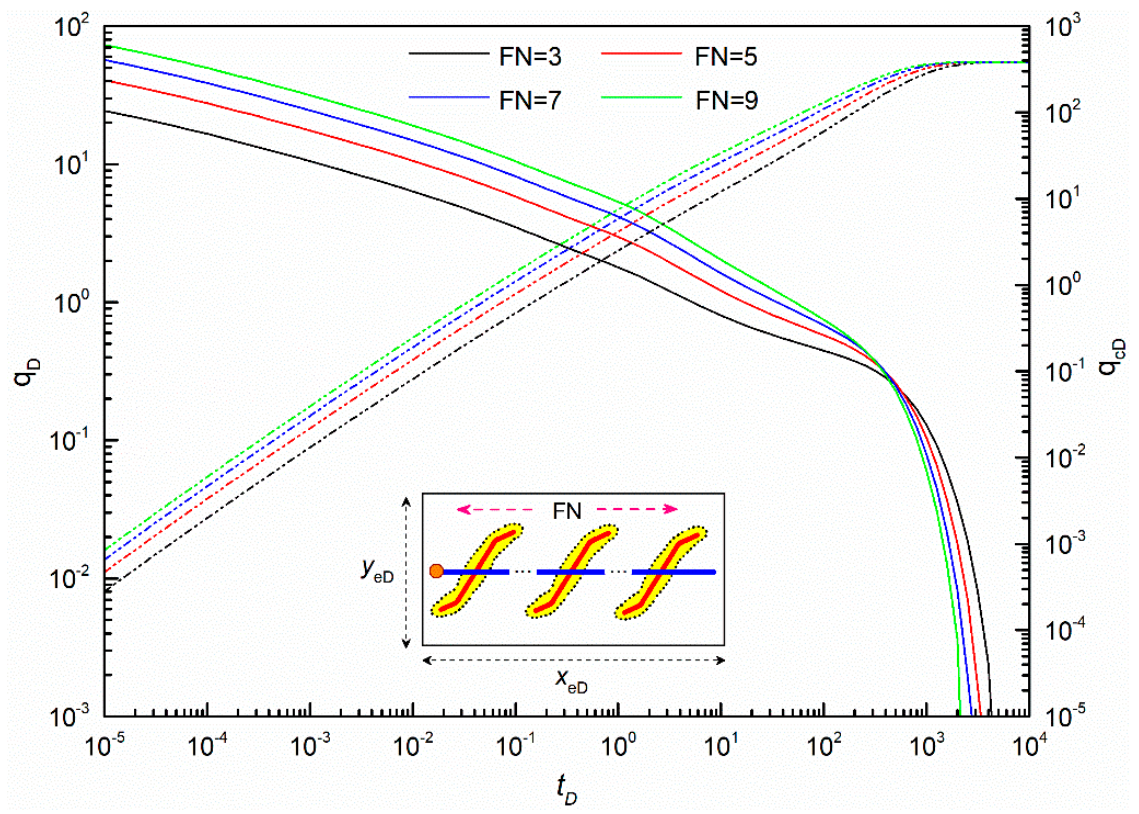

Figure 13. Effect of reorientation fracture number on the rate decline and cumulative production.

As seen from Figure 13, both the rate-decline and cumulative-production curves are affected by the reorientation fracture number in the whole flow period. Before the boundary-dominant flow, the transient rate increases as the reorientation fracture number increases. However, the increase in the transient rate slows down when the reorientation fracture number reaches a certain degree. For a fixed, tight reservoir and given fracture spacing, when the fracture number is large enough, the seepage area affected by reorientation fractures almost no longer expands with the increase in the fracture number, which reveals the reason for the above phenomenon. However, in the boundary-dominant flow period, the transient rate is inversely proportional to the reorientation fracture number while cumulative production tends to remain consistent.

Based on the analysis results of fracture spacing (Figure 12) and the fracture number (Figure 13), it can be concluded that for a fixed, tight reservoir, there is an optimal matching relationship between fracture spacing and the fracture number for a refractured horizontal well with multiple reorientation fractures to achieve the economic production. 


\subsubsection{Reservoir Permeability Anisotropy}

Permeability anisotropy always occurs in slab or rectangular reservoirs and brings uncertainty to well production, which is also an important factor to consider in the optimization of horizontal wellbore deployment and fracture propagation direction. Considering the characteristics of fracture reorientation, it is necessary to explore the potential effect of permeability anisotropy on well production. Figure 14 displays the effect of permeability anisotropy on the transient rate and cumulative production of a refractured horizontal well in an anisotropic tight reservoir $(\beta=1,2,3,4)$.

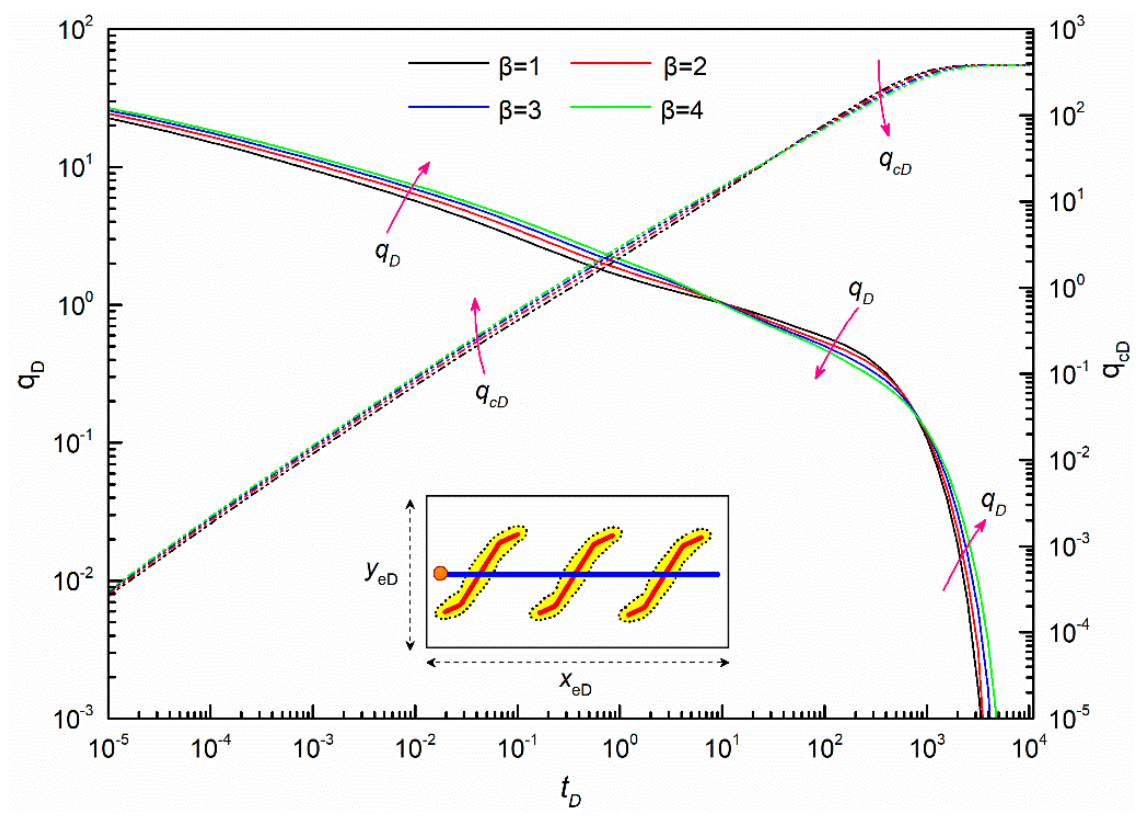

Figure 14. Effect of permeability anisotropy on the rate decline and cumulative production.

As shown in Figure 14, permeability anisotropy slightly affects the transient rate and cumulative production in the whole flow period. In the early flow period, both the transient rate and cumulative production increases as the permeability anisotropic factor increases for a fixed fracture network. This feature results from the fact that the increase in the permeability anisotropic factor results in low flow resistance in the $x$-direction and this direction dominates the fluid flow. However, in the middle flow period, the flow in the isotropic reservoir $(\beta=1)$ is relatively balanced compared with the flow in the anisotropic reservoir, which leads to the decrease in the transient rate and cumulative production with the intensification of permeability anisotropy. In the boundary-dominant flow period, the relationship between the production rate and permeability anisotropy is reversed again while the cumulative production for all cases remains similar. In total, when one reservoir has strong permeability anisotropy, the match between the reorientation fracture angle and the principal permeability direction cannot be ignored.

\subsection{Multifactor Sensitivity Analysis of Traditional Rate Decline}

In order to further investigate the comprehensive effects of reorientation fracture properties on the production rate, based on the related parameter values in Table 3, two production rate surface graphs with dual fracture parameters at different production times $\left(t_{D}=10^{-5}, 10^{-4}\right.$, and $\left.10^{-3}\right)$ were plotted for multifactor sensitivity analysis, shown in Figures 15 and 16. 


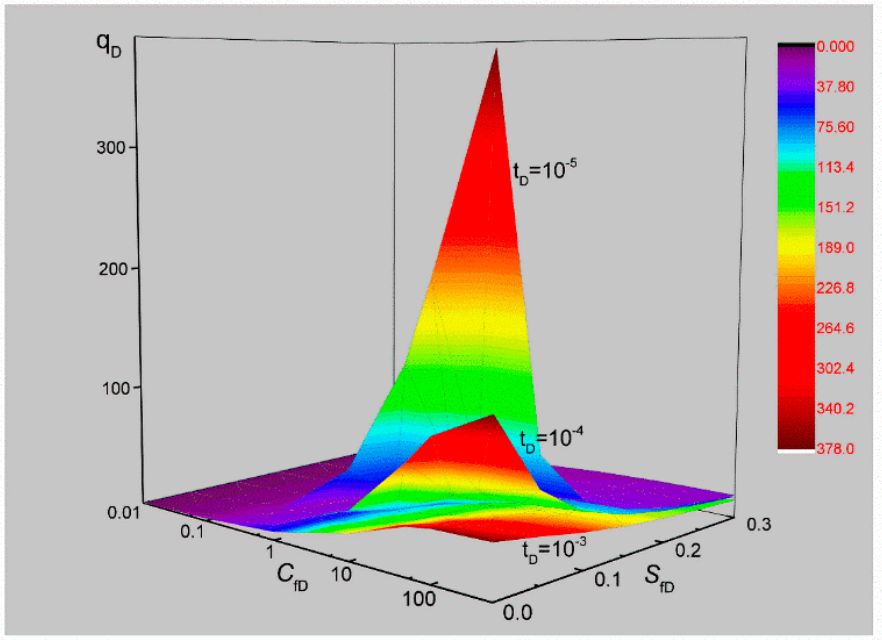

Figure 15. Effect of fracture conductivity and fracture face damage on the rate decline.

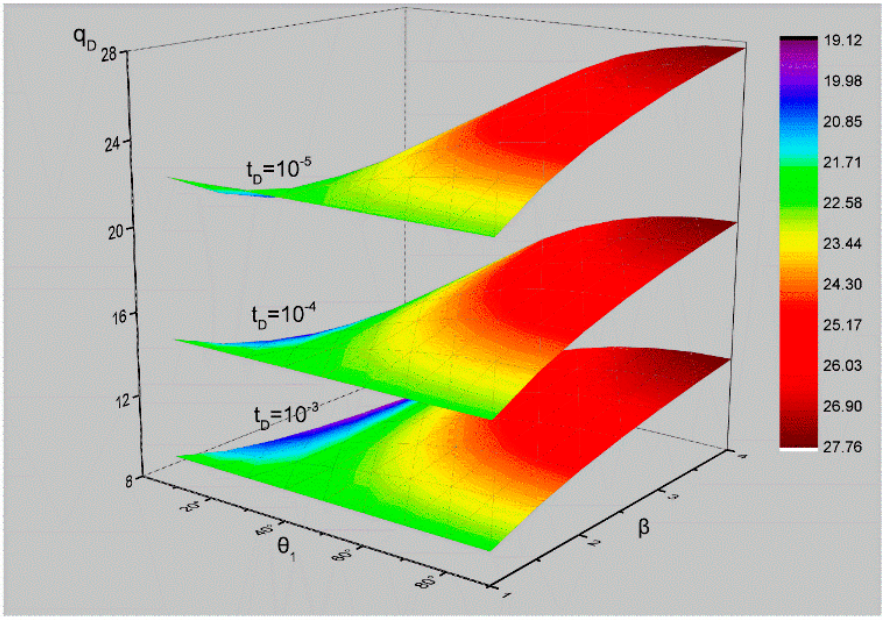

Figure 16. Effect of fracture angle and permeability anisotropy on the rate decline.

Figure 15 presents the combined effects of fracture conductivity and fracture face damage on the transient rate at different times. It can be seen that in the early production period, a high production rate can be obtained if the fracture conductivity approaches infinity and fracture face damage is close to zero. The production rate in this stage tends to be zero when fracture conductivity is very low, while there is still a low production rate when fracture face damage becomes serious. In contrast, fracture conductivity has a more sensitive effect on well production than fracture face damage, indicating that fracture conductivity should be as high as possible to obtain higher productivity during refracturing.

Figure 16 demonstrates the combined effects of the fracture angle and permeability anisotropy on the transient rate at different times. It can be observed that the effect of the fracture angle on the production rate can be neglected in an isotropic reservoir $(\beta=1)$. However, for an anisotropic reservoir, the effect of the fracture angle is evident and higher production can be obtained when the fracture angle increases to some degree. Once again, it shows that there is an optimal matching relationship between the principal fracture section angle and permeability anisotropy for tight reservoirs with strong permeability anisotropy. When permeability anisotropy is strong enough, the effect of the fracture angle on the production rate becomes more sensitive, and the principal fracture section should be perpendicular to the principal permeability direction ( $x$-axis) to achieve maximum productivity. 


\subsection{Blasingame Type Rate Decline Curves}

In this subsection, based on the proposed Blasingame-type rate decline solution, a series of Blasingame-type rate decline curves were presented for a refractured horizontal well under different reorientation fracture properties. On one hand, the typical characteristics of Blasingame-type decline curves were investigated for a refractured horizontal well; on the other hand, by assigning the same parameter values, the difference between the traditional rate decline curves and Blasingame-type decline curves was compared.

5.3.1. Typical Characteristics of Blasingame Type Rate Decline Curves for a Refractured Horizontal Well

Figure 17 shows the identification of flow regimes of Blasingame-type curves for a refractured horizontal well. As demonstrated in Figure 17, Blasingame-type curves can be divided into six typical flow regimes: (I) The bi-linear flow regime, which reflects the fluid linearly flowing from a tight formation into reorientation fractures and then linearly flowing into the horizontal wellbore; (III) the first linear flow regime, reflecting the flow near reorientation fracture face; $(\mathrm{V})$ the mid-radial flow regime, reflecting the flow around each reorientation fracture; (VI) the mid-linear flow regime, reflecting the flow around all the reorientation fractures; (VII) the pseudo-radial flow regime, reflecting the flow in the tight formation; and (IX) the boundary-dominant flow regime, indicating that the pressure drop wave reaches the closed boundaries and the horizontal well production is approaching its limit.

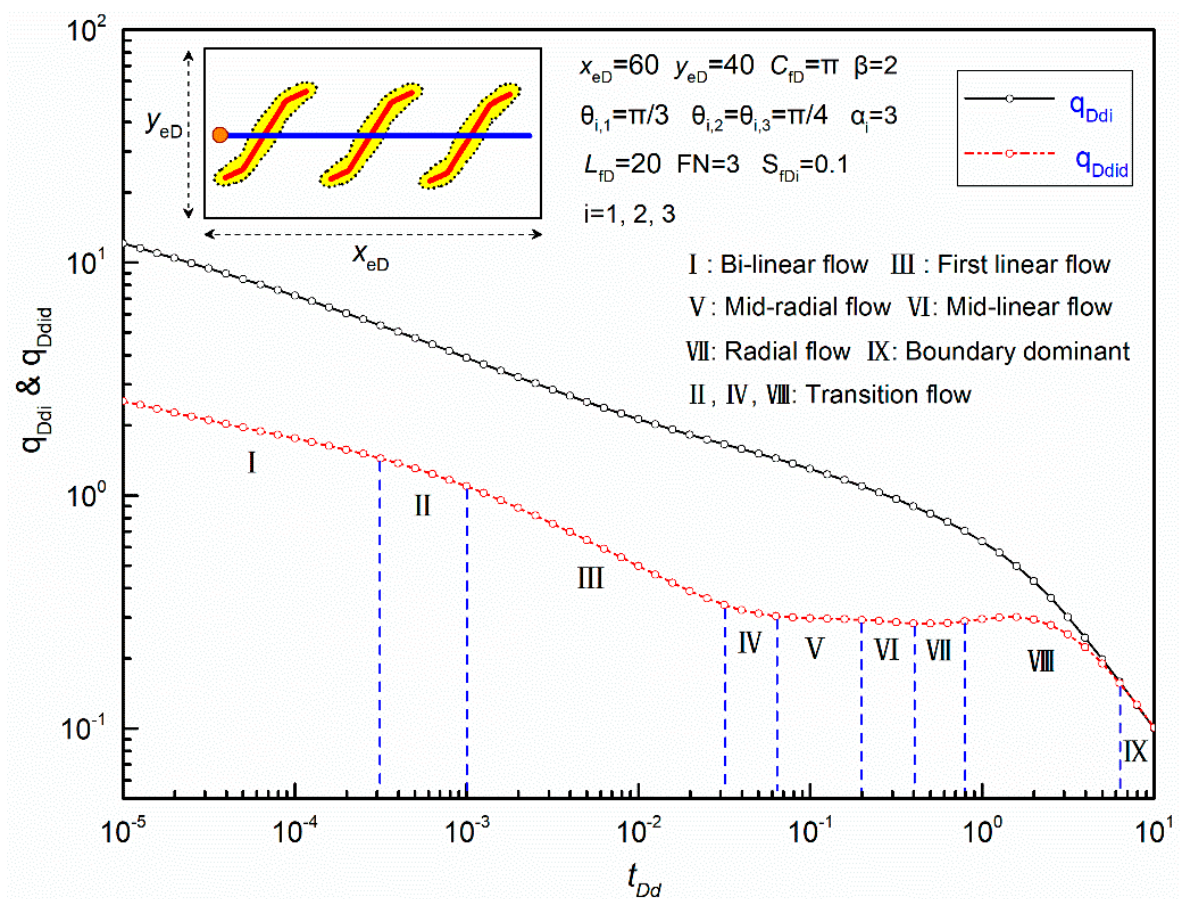

Figure 17. Flow regimes of Blasingame-type curves for a refractured horizontal well intercepted by multiple reorientation fractures with fracture face damage.

\subsubsection{Blasingame Type Rate Decline Curves for a Refractured Horizontal Well}

Combined with the previous single-factor sensitivity analysis, four parameters including fracture face damage, the principal fracture section angle, the fracture number, and permeability anisotropy are selected to draw the corresponding Blasingame-type rate decline curves using the same parameter values, as presented in Figure 18a-d. 


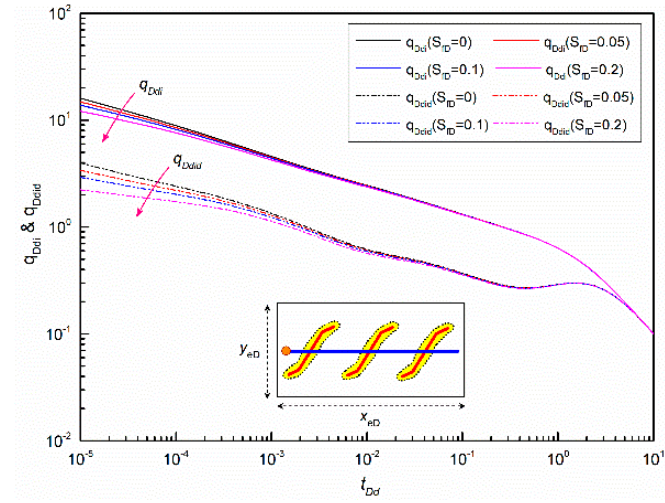

(a)

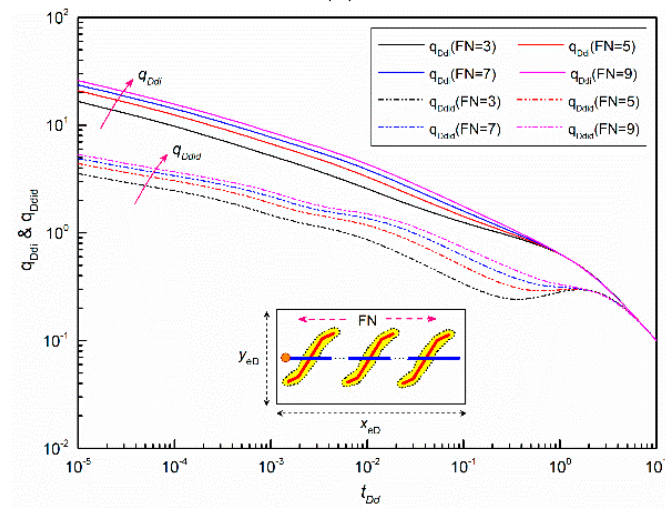

(c)

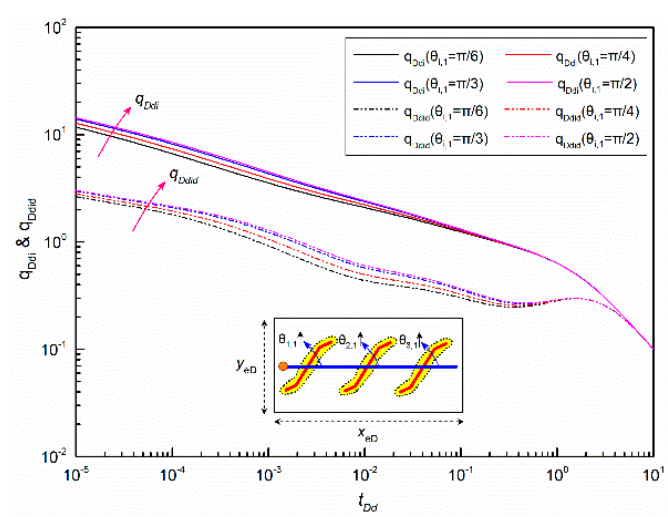

(b)

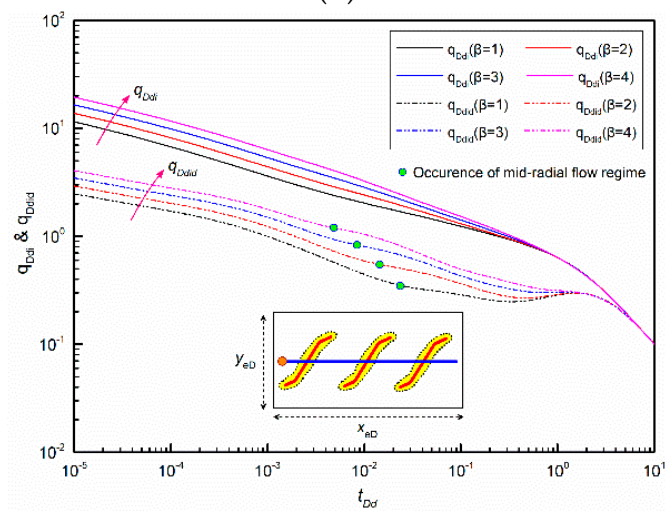

(d)

Figure 18. Blasingame-type rate decline curves under different fracture and reservoir parameters. (a) Fracture face damage $\left(S_{f D}=0,0.05,0.1,0.2\right)$. (b) Principal fracture section angle $\left(\theta_{i, 1}=\pi / 6, \pi / 4, \pi / 3, \pi / 2\right)$. (c) Fracture number $(F N=3,5,7,9)$. (d) Permeability anisotropy $(\beta=1,2,3,4)$.

Figure 18a shows the effect of facture face damage on Blasingame-type decline curves. It can be observed that the fracture face damage mainly affects the early linear flow regimes $\left(t_{D} \leq 10^{-1}\right)$, which is the same as the effect of fracture face damage on traditional rate decline (Figure 7). Both the normalized cumulative production $\left(q_{D d i}\right)$ and the integral derivative of normalized cumulative production $\left(q_{\text {Ddid }}\right)$ show negative correlations with fracture face damage. Figure 18b illustrates that the principal fracture angle section has a significant influence on the regimes of bi-linear flow, first linear flow, and mid-radial flow of Blasingame-type curves, and both the normalized cumulative production and the integral derivative increase with the increase in the principal fracture section angle, which is also similar to its influence on traditional rate decline (Figure 8). Figure $18 \mathrm{c}$ demonstrates that the reorientation fracture number has a positive correlation with the Blasingame-type rate in all flow regimes except the boundary-dominant flow regime, similar to its impact on the instantaneous rate (Figure 13). However, the increase in $q_{D d i}$ and $q_{\text {Ddid }}$ slows and the radial flow regime tends to disappear (violet dash dot) when the reorientation fracture number increases to some degree. Figure $18 \mathrm{~d}$ indicates permeability anisotropy also affects Blasingame-type curves in all flow regimes except the boundary-dominant flow regime and shows a positive relationship with the Blasingame-type rate, which is different from the multiple relationship inversions in Figure 14. In the bi-linear and first linear flow regimes, the curves of $q_{D d i}$ and $q_{\text {Ddid }}$ are almost parallel to each other for different permeability anisotropy. Furthermore, the increment in $q_{D d i}$ in the mid-radial flow regime tends to slow and the mid-radial flow regime appears earlier.

By comparing the traditional rate decline curves and Blasingame-type rate decline curves of the same sensitive factor it can be concluded that the flow characteristics of Blasingame-type curves are more obvious and typical considering the identification of the 
typical flow regimes. The combination of two types of rate decline curves can help the well test inversion to obtain the model parameters.

\subsection{Field Application}

In this subsection, we use the proposed semi-analytical model to conduct a type-curve fitting on production well S in Ordos Basin, China. This well is located in a typical tight oil zone. The performance of this well after initial fracturing is presented with low oil production and nearly no water production. Its productivity is obviously lower than that of the adjacent well after initial fracturing. Considering the similar reservoir quality, their productivity difference is speculated to be mainly caused by hydraulic fracturing. Later, a refracturing treatment was conducted for this well. By applying the derived Blasingametype rate decline solution, a type-curve fitting for the production data of well $\mathrm{S}$ is employed to estimate its fracture parameters, shown in Figure 19. The basic data obtained from the well test inversions are as follows: $F N=5, L_{f}=120 \mathrm{~m}, k_{f}=2040 \times 10^{-3} \mu \mathrm{m}^{2}, \theta_{i, 1}=60^{\circ}$, $\theta_{i, 2}=\theta_{i, 3}=45^{\circ}, \alpha_{i}=3, S_{f D}=0.2$. It is not convenient to specify other parameters because of the relative policy of China. Based on these estimated parameters, we can predict the future rate decline by using the traditional rate decline solution.

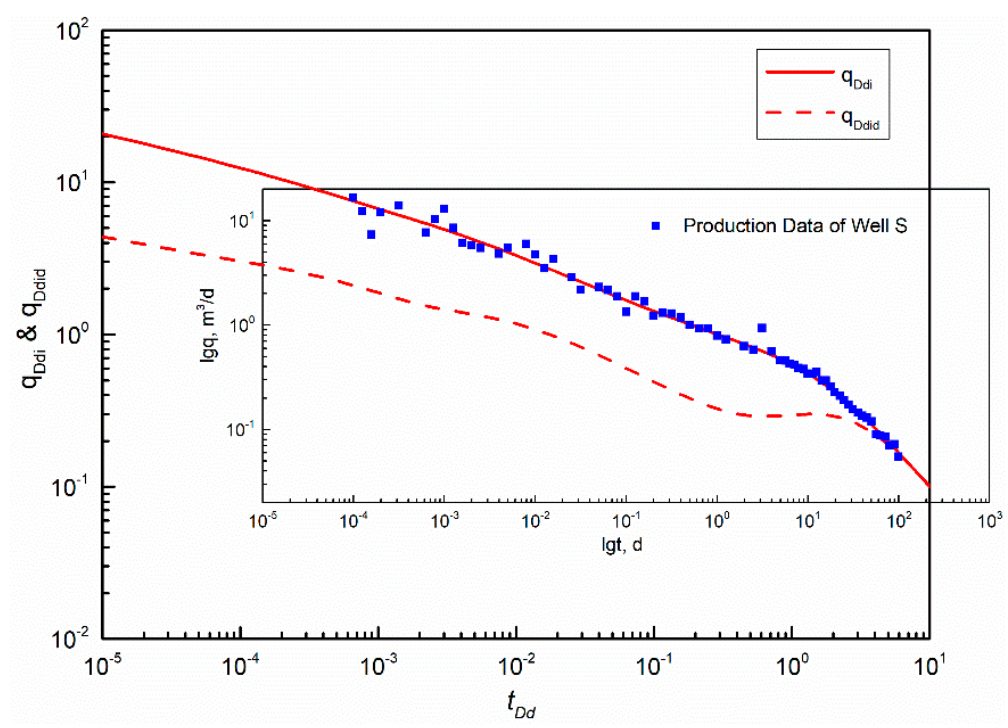

Figure 19. Type-curve matching and parameter estimations for refractured well $\mathrm{S}$ in Ordos Basin.

\section{Conclusions}

This paper presents two rate decline solutions for a refractured horizontal well with fracture face damage in an anisotropic tight reservoir. Based on our model and the results, the main conclusions can be drawn as follows:

1. By using a semi-analytical method, traditional and Blasingame-type rate decline solutions in the Laplace domain were developed for a refractured horizontal well intercepted by multiple reorientation fractures with fracture face damage in an anisotropic tight reservoir. The proposed traditional rate decline solution shows good agreement with a classic case in the literature and a numerical simulation case.

2. Single-factor sensitivity analysis of traditional rate decline shows that fracture face damage is not conducive to increasing well productivity during the early flow period. A larger fracture face, which is as perpendicular to the principal permeability direction as possible, is helpful to improve flow efficiency. There is an optimal matching relationship between the principal fracture section angle, the fracture length ratio, and permeability anisotropy for strong anisotropic reservoirs.

3. Fracture spacing has a weak effect on the production rate while the fracture number shows a strong influence on the rate decline. It is unwise to ignore the influence of a lower fracture number in order to pursue wider fracture spacing. The matching 
relationship between fracture spacing and the fracture number for a refractured horizontal well needs to be optimized for economical production.

4. Multifactor sensitivity analysis of the transient rate decline shows that fracture conductivity has a more sensitive effect on the productivity than fracture face damage, and large fracture conductivity should be pursued. Under strong permeability anisotropy, the principal fracture section angle becomes more sensitive to the production rate than permeability anisotropy, and the principal fracture section should be perpendicular to the principal permeability direction to achieve maximum productivity.

5. Six typical flow regimes can be identified from Blasingame-type rate decline curves, including the bi-linear flow regime, first linear flow regime, mid-radial flow regime, mid-linear flow regime, pseudo-radial flow regime, and boundary-dominant flow regime. Various fracture properties are sensitive to different flow regimes. The flow characteristics of Blasingame-type curves are more obvious and typical than traditional rate decline curves. The combination of two kinds of rate decline curves can help the well test inversion to obtain the model parameters.

Author Contributions: Conceptualization, M.W. and X.D.; methodology, M.W. and X.D.; validation, M.W. and W.Z.; formal analysis, X.D., R.M., and W.L.; investigation, X.D., R.M., and W.L.; data curation, M.W. and W.Z.; writing-original draft preparation, M.W. and X.D.; writing-review and editing, M.W., X.D. and C.T.; supervision, C.T.; project administration, C.T.; funding acquisition, X.D. and M.W. All authors have read and agreed to the published version of the manuscript.

Funding: This study was funded by the National Natural Science Foundation of China (Program No. 52004038 \& 52104031), the CNPC Innovation Foundation (Program No. 2020D-5007-0201), the Natural Science Basic Research Program of Shaanxi (Program No. 2021JQ-596), and the National Science and Technology Major Project of China (Program No. 2016ZX05046-003).

Institutional Review Board Statement: Not applicable.

Informed Consent Statement: Not applicable.

Data Availability Statement: All data have been included in the manuscript.

Conflicts of Interest: The authors declare no conflict of interest.

\section{Nomenclature}

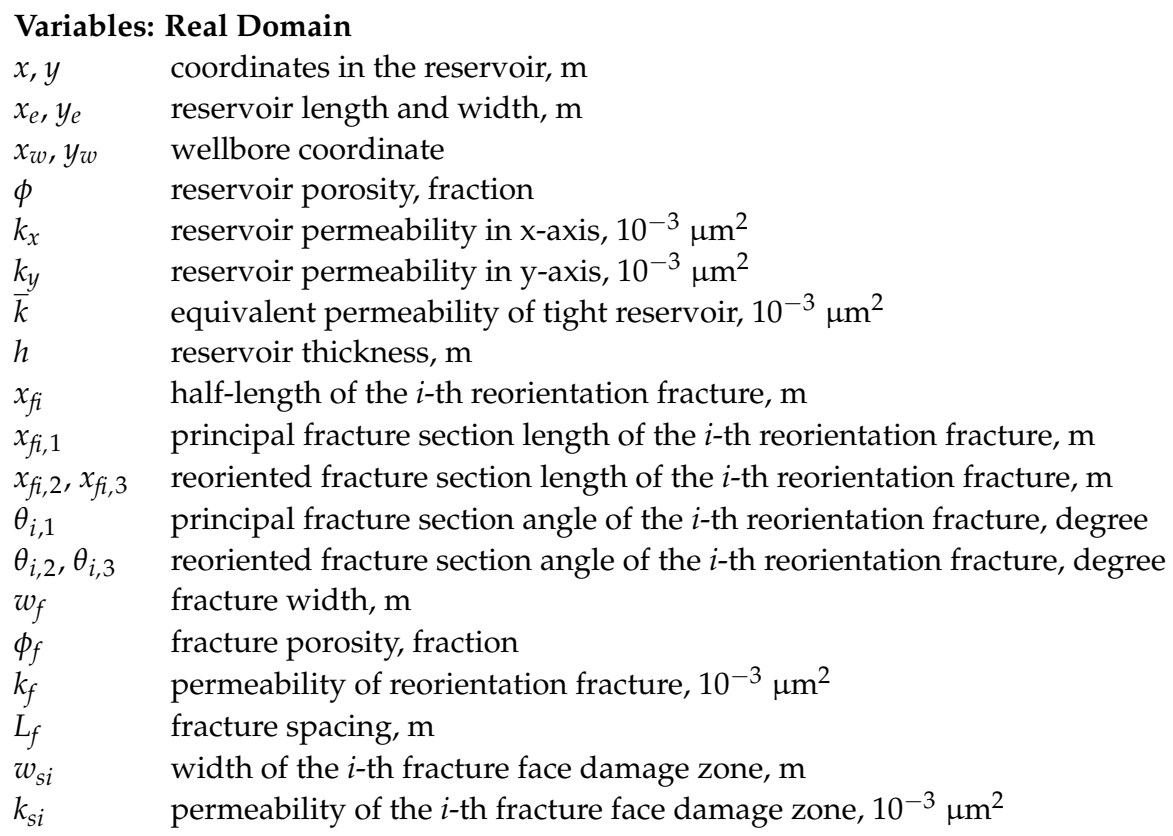




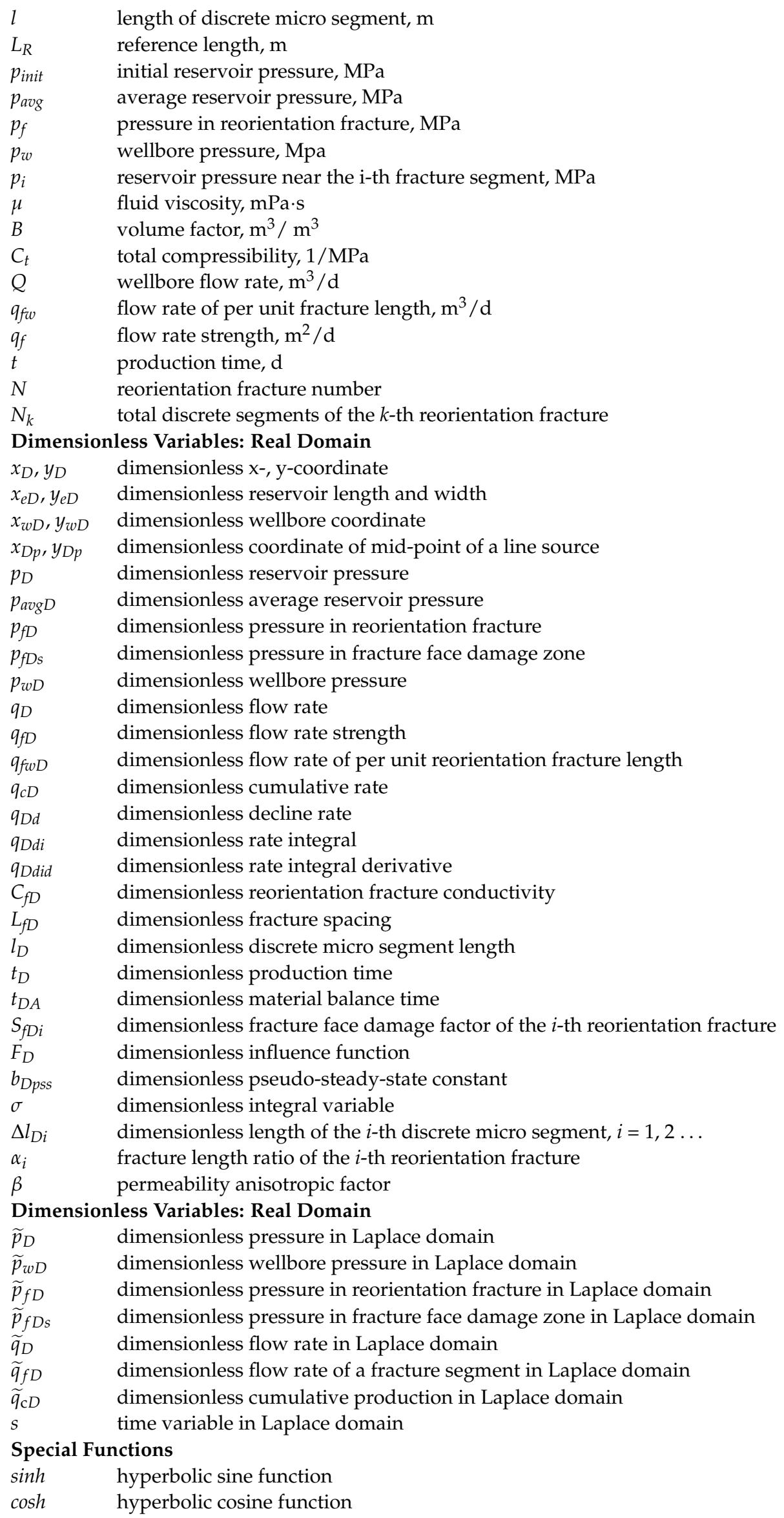




\section{References}

1. Lantz, T.G.; Greene, D.T.; Eberhard, M.J.; Norrid, R.S.; Pershall, R.A. Refracture treatments proving successful in horizontal Bakken wells: Richland Count, Montana. In Proceedings of the Rocky Mountain Oil \& Gas Technology Symposium, Denver, CO, USA, 16-18 April 2007; pp. 1-8. [CrossRef]

2. Indras, P.; Blankenship, C. A commercial evaluation of refracturing horizontal shale wells. In Proceedings of the SPE Annual Technical Conference and Exhibition, Houston, TX, USA, 28-30 September 2015; pp. 1-14. [CrossRef]

3. Lindsay, G.J.; White, D.J.; Miller, G.A.; Baihly, J.D.; Sinosic, B. Understanding the applicability and economic viability of refracturing horizontal wells in unconventional plays. In Proceedings of the SPE Hydraulic Fracturing Technology Conference, The Woodlands, TX, USA, 9-11 February 2016; pp. 1-19. [CrossRef]

4. Wright, C.A. Reorientation of propped refracture treatments in the Lost Hills Field. In Proceedings of the SPE Western Regional Meeting, Long Beach, CA, USA, 23-25 March 1994; pp. 483-497. [CrossRef]

5. Siebrits, E.; Elbel, J.L.; Detournay, E.; Detournay-Piette, C.; Christianson, M.; Robinson, B.M.; Diyashev, I.R. Parameters affecting azimuth and length of a secondary fracture during a refracture treatment. In Proceedings of the SPE Annual Technical Conference and Exhibition, New Orleans, LA, USA, 27-30 September 1998; pp. 17-27. [CrossRef]

6. $\quad$ Siebrits, E.; Elbel, J.L.; Hoover, R.S.; Diyashev, I.R.; Griffin, L.G.; Demetrius, S.L.; Wright, C.A.; Davidson, B.M.; Steinsberger, N.P.; Hill, D.G. Refracture reorientation enhances gas production in Barnett shale tight gas wells. In Proceedings of the SPE Annual Technical Conference and Exhibition, Dallas, TX, USA, 1-4 October 2000; pp. 1-7. [CrossRef]

7. Evans, J.G. The use of pressure buildup information to analyze non-respondent vertically fractured oil wells. In Proceedings of the SPE Rocky Mountain Regional Meeting, Billings, MT, USA, 2-4 June 1971; pp. 1-10. [CrossRef]

8. Ilk, D.; Currie, S.M.; Symmons, D.; Rushing, J.A.; Blasingame, T.A. Hybrid rate-decline models for the analysis of production performance in unconventional reservoirs. In Proceedings of the SPE Annual Technical Conference and Exhibition, Florence, Italy, 19-22 September 2010; pp. 1-39. [CrossRef]

9. Li, P.Y.; Hao, M.Q.; Hu, J.H.; Ru, Z.X.; Li, Z.P. A new production decline model for horizontal wells in low-permeability reservoirs. J. Petrol. Sci. Eng. 2018, 171, 340-352. [CrossRef]

10. Luo, H.; Mahiya, G.F.; Pannett, S.; Benham, P. The use of rate-transient-analysis modeling to quantify uncertainties in commingled tight gas production-forecasting and decline-analysis parameters in the Alberta Deep Basin. SPE Reserv. Eval. Eng. 2014, 17, 209-219. [CrossRef]

11. Tian, F.; Du, X.K.; Wang, X.D.; Xu, W.L. Rate decline analysis for finite conductivity vertical fractured gas wells produced under a variable inner boundary condition. J. Petrol. Sci. Eng. 2018, 171, 1249-1259. [CrossRef]

12. Chen, Z.M.; Liao, X.W.; Zhao, X.L.; Yu, W.; Sepehrnoorib, K. A workflow based on a semianalytical model to estimate the properties of stimulated reservoir volume of tight-oil wells. J. Petrol. Sci. Eng. 2019, 178, 892-903. [CrossRef]

13. Jiang, L.W.; Liu, J.J.; Liu, T.J.; Yang, D.Y. Production decline analysis for a fractured vertical well with reorientated fractures in an anisotropic formation with an arbitrary shape using the boundary element method. J. Petrol. Sci. Eng. 2021, 109213, in press. [CrossRef]

14. Arps, J.J. Analysis of decline curves. Pet. Trans. 1945, 160, 228-247. [CrossRef]

15. Fetkovich, M.J. Decline curve analysis using type curves. J. Pet. Tech. 1980, 32, 1065-1077. [CrossRef]

16. Blasingame, T.A.; Johnston, J.L.; Lee, W.J. Type-curve analysis using the pressure integral method. In Proceedings of the SPE California Regional Meeting, Bakersfield, CA, USA, 5-7 April 1989; pp. 1-19. [CrossRef]

17. Blasingame, T.A.; McCray, T.L.; Lee, W.J. Decline curve analysis for variable pressure drop/variable flowrate systems. In Proceedings of the SPE Gas Technology Symposium, Houston, TX, USA, 22-24 January 1991; pp. 1-17. [CrossRef]

18. Andersen, P.Ø. A semi-analytical solution for shale gas production from compressible matrix including scaling of gas recovery. $J$. Nat. Gas Sci. Eng. 2021, 95, 1-23. [CrossRef]

19. Nobakht, M.; Clarkson, C.R. A new analystical method for analyzing linear flow in tight/shale gas reservoirs: Constant-flowingpressure boundary condition. SPE Reserv. Eval. Eng. 2012, 15, 370-384. [CrossRef]

20. Agarwal, R.G.; Carter, R.D.; Pollock, C.B. Evaluation and performance prediction of low-permeability gas wells stimulated by massive hydraulic fracturing. J. Pet. Tech. 1979, 31, 362-372. [CrossRef]

21. Cinco-Ley, H.; Samaniego-V, F. Transient pressure analysis for fractured wells. J. Pet. Technol. 1981, 33, 1749-1766. [CrossRef]

22. Clarkson, C.R.; Beierle, J. Integration of microseismic and other post-fracture surveillance with production analysis: A tight gas study. In Proceedings of the SPE Unconventional Gas Conference, Pittsburgh, PA, USA, 23-25 February 2010; pp. 1-32. [CrossRef]

23. Chen, H.; Teufel, L.W. A new rate-time type curve for analysis of tight-gas linear and radial flows. In Proceedings of the SPE Annual Technical Conference and Exhibition, Dallas, TX, USA, 1-4 October 2000; pp. 1-12. [CrossRef]

24. Zhang, D.L.; Zhang, L.H.; Guo, J.J.; Zhou, Y.H.; Zhao, Y.L. Research on the production performance of multistage fractured horizontal well in shale gas reservoir. J. Nat. Gas Sci. Eng. 2015, 26, 279-289. [CrossRef]

25. Wang, J.H.; Wang, X.D.; Dong, W.X. Rate decline curves analysis of multiple-fractured horizontal wells in heterogeneous reservoirs. J Hydrol. 2017, 553, 527-539. [CrossRef]

26. He, Y.W.; Cheng, S.Q.; Rui, Z.H.; Qin, J.Z.; Fu, L.; Shi, J.G.; Wang, Y.; Li, D.Y.; Patil, S.; Yu, H.Y.; et al. An improved rate-transient analysis model of multi-fractured horizontal wells with non-uniform hydraulic fracture properties. Energies 2018, 11, 393. [CrossRef] 
27. Hu, Y.P.; Cheng, Z.Y.; Ding, W.; Zhang, X.L.; Qu, L.C.; Sun, C.L.; Su, P.H.; Zhang, W.Q. Rate decline analysis of horizontal wells with multiple variable conductivity and uneven distributed fractures. Geofluids 2020, 2020, 8854307. [CrossRef]

28. Teng, B.L.; Li, H.Z.A. A Semi-analytical model for evaluating the performance of a refractured vertical well with an orthogonal refracture. SPE J. 2019, 24, 891-911. [CrossRef]

29. Wu, S.H.; Xing, G.Q.; Cui, Y.D.; Wang, B.H.; Shi, M.Y.; Wang, M.X. A semi-analytical model for pressure transient analysis of hydraulic reorientation fracture in an anisotropic reservoir. J. Petrol. Sci. Eng. 2019, 179, 228-243. [CrossRef]

30. Wang, M.X.; Fan, Z.F.; Zhao, L.; Xing, G.Q.; Zhao, W.Q.; Tan, C.Q. Productivity analysis for a horizontal well with multiple reorientation fractures in an anisotropic reservoir. Oil Gas Sci. Technol. 2020, 75, 1-17. [CrossRef]

31. Grieser, B.; Calvin, J.; Dulin, J. Lessons learned: Refracs from 1980 to present. In Proceedings of the SPE Hydraulic Fracturing Technology Conference, The Woodlands, TX, USA, 9-11 February 2016; pp. 1-24. [CrossRef]

32. Asalkhuzina, G.F.; Davletbaev, A.Y.; Fedorov, A.I.; Yuldasheva, A.R.; Efremov, A.N.; Sergeychev, A.V.; Ishkin, D.Z. Identification of refracturing reorientation using decline-analysis and geomechanical simulator. In Proceedings of the SPE Russian Petroleum Technology Conference, Moscow, Russia, 16-18 October 2017; pp. 1-11. [CrossRef]

33. Cinco-Ley, H.; Samaniego, V.F. Effect of wellbore storage and damage on the transient pressure behavior of vertically fractured wells. In Proceedings of the SPE Annual Fall Technical Conference and Exhibition, Denver, CO, USA, 9-12 October 1977; pp. 1-8. [CrossRef]

34. Wang, L.; Wang, X.D.; Ding, X.M.; Zhang, L.; Li, C. Rate decline curves analysis of a vertical fractured well with fracture face damage. J Energ. Resour. ASME 2012, 134, 1-9. [CrossRef]

35. Xing, G.Q.; Wu, S.H.; Wang, J.H.; Wang, M.X.; Wang, B.H.; Cao, J.J. Pressure transient performance for a horizontal well intercepted by multiple reorientation fractures in a tight reservoir. Energies 2019, 12, 4232. [CrossRef]

36. Duhamel, J.M.C. Study on general method of solid thermal motion in medium with temperature varying with time. J. l'Ecole Polytech. (Paris) 1833, 14, 20-27.

37. Wang, X.D. Fundamental Mechanics of Fluids Flow in Porous Media; Petroleum Industry Press: Beijing, China, 2006.

38. Stehfest, H. Numerical inversion of Laplace transforms. Commun. ACM 1970, 13, 47-49. [CrossRef]

39. Pratikno, H.; Rushing, J.A.; Blasingame, T.A. Decline curve analysis using type curves-fractured wells. In Proceedings of the SPE Annual Technical Conference and Exhibition, Denver, CO, USA, 5-8 October 2003; pp. 1-14. [CrossRef]

40. Cui, Y.D.; Lu, B.; Wu, M.T.; Luo, W.J. A new pseudo steady-state constant for a vertical well with finite-conductivity fracture. Processes 2018, 6, 93. [CrossRef]

41. Xing, G.Q.; Wang, M.X.; Wu, S.H.; Li, H.; Dong, J.Y.; Zhao, W.Q. Pseudo-steady-state Parameters for a well penetrated by a fracture with an azimuth angle in an anisotropic reservoir. Energies 2019, 12, 2449. [CrossRef]

42. Luo, W.J.; Tang, C.F.; Feng, Y.; Zhu, M.Y. Mechanism of fluid flow along a dynamic conductivity fracture with pressure-dependent permeability under constant wellbore pressure. J. Petrol. Sci. Eng. 2018, 166, 465-475. [CrossRef] 